Canadian

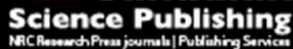

Canadian Geotechnical Journal Revue canadienne de géotechnique

\title{
Permeability function for oil sands tailings undergoing volume change during drying
}

\begin{tabular}{|r|l|}
\hline Journal: & Canadian Geotechnical Journal \\
\hline Manuscript ID & cgj-2016-0486.R2 \\
\hline Danuscript Type: & Article \\
\hline Complete List of Authors: & $\begin{array}{l}\text { Zhang, Feixia; University of Alberta, Civil and Environmental Engineering } \\
\text { Wilson, Ward; University of Alberta, Civil \& Environmental Engineering } \\
\text { Fredlund, Delwyn; Golder Associates Ltd., Geotechnical Engineering }\end{array}$ \\
\hline Keyword: & $\begin{array}{l}\text { permeability function, SWCC, degree of saturation, volume change, oil } \\
\text { sands tailings }\end{array}$ \\
\hline \multicolumn{2}{|c}{} \\
\hline
\end{tabular}




\section{Permeability function for oil sands tailings undergoing volume change during drying}

Feixia Zhang ${ }^{1}$, G. Ward Wilson ${ }^{2}$ and D.G. Fredlund ${ }^{3}$

${ }^{1} \mathrm{PhD}$ Candidate, Department of Civil and Environmental Engineering, University of Alberta, Edmonton, AB, feixia@ualberta.ca

2 Professor, Department of Civil and Environmental Engineering, University of Alberta, Edmonton, AB, wwilson2@ualberta.ca

3 Senior Geotechnical Engineer, Golder Associates Ltd., Saskatoon, SK., Canada, delwyn.fredlund@gmail.com

Corresponding author: Feixia Zhang

Address: Department of Civil \& Environmental Engineering, University of Alberta, Markin/CNRL Natural Resources Engineering Facility, $9105-116^{\text {th }}$ ST, Edmonton, Alberta, Canada, T6G 2W2 Telephone number: 5879367383

E-mail Address: feixia@ualberta.ca 


\section{Abstract:}

The coefficient of permeability function is an important unsaturated soil property required when modeling seepage and contaminant transport phenomena. Inaccuracies in the estimation of the permeability function can lead to significant errors in numerical modeling results. Changes in void ratio and degree of saturation are factors that influence the permeability function. Presently available methodologies for estimating the unsaturated permeability function make the assumption that there is no volume change as soil suction is changed. As a result, volume changes are interpreted as changes in degree of saturation. The commonly used estimation techniques for the permeability function are reasonable for soils such as sands that experience little volume change as soil suction is changed. On the other hand, inaccurate results are generated when soils undergo volume change as is the case with oil sands tailings. Revisions to previous methodologies are proposed to render the estimation of the permeability function more suitable for simulating the drying process associated with high volume-change soils. The revised methodology independently analyzes the effect of volume changes (i.e., changes in void ratio), and degree of saturation changes (i.e., changes in S-SWCC). Laboratory data on thickened oil sands tailings are presented and interpreted within the context of the proposed methodology.

Key words: permeability function, SWCC, degree of saturation, volume change, oil sands tailings. 


\section{Glossary}

$e=$ void ratio,

$G_{s}=$ specific gravity of the solids,

$S=$ degree of saturation,

$S_{0}=$ initial degree of saturation,

$w=$ gravimetric water content,

$w_{s}=$ initial saturated gravimetric water content,

$\theta=$ volumetric water content where the volume of water is referenced to the initial total

volume of the tested soil,

$\theta_{i}=$ instantaneous volumetric water content where the volume of water is referenced to the instantaneous total volume of the tested soil,

$\theta_{s}=$ saturated volumetric water content,

$\psi=$ soil suction, 


\section{Introduction}

The oil sands bitumen extraction process in northern Alberta produces large volumes of high water content tailings composed of sand, silt, clay, and a small amount of unrecovered bitumen. Significant portions of the fines remain in suspension after deposition resulting in a tailings management challenge for the industry. Various processes and technologies have been suggested to improve the water release characteristics of the tailings. One of the disposal methodologies advanced to improve the dewatering behavior of the tailings is thin lift deposition of thickened oil sands tailings (TT) (Sobkowicz and Morgenstern 2009; BGC Engineering Inc 2010). The design of tailings disposal often involves numerical modeling of TT at various sandto-fines ratios, (SFRs) (Zhang et al. 2014). Numerical modeling of the dewatering process requires the use of an appropriate permeability function and water storage function.

Research has shown that changes in the void ratio and changes in the degree of saturation are factors that influence the permeability function of a soil (Zhang et al. 2014). The effect of changing void ratio on changes in the saturated coefficient of permeability has previously been given consideration (Chapuis 2012; Taylor 1948). Methodologies for the estimation of the permeability function for an unsaturated soil are usually based on the assumption that no volume change occurs as soil suction is changed. In other words, changes in the permeability of an unsaturated soil are assumed to occur as a result of changes in degree of saturation. Reasonable permeability functions can be obtained for unsaturated soils that do not undergo volume change as soil suction is changed (Fredlund et al. 2012). Oil sands tailings have been found to undergo significant volume change as soil suction is increased during drying (Fredlund et al. 2011). Commonly used unsaturated permeability estimation methodologies cannot adequately represent the permeability function for oil sands tailings subjected to drying.

This paper proposes a methodology for the estimation of the permeability function for soils that undergo volume change as soil suction is increased. Changes in void ratio and degree of 
saturation are taken into account as two independent factors of significance. Laboratory test results are used to illustrate the application of the proposed methodology for oil sands tailings. The extreme nonlinearity in the gravimetric water content versus soil suction relationship (i.e., w-SWCC) can make it difficult to accurately best-fit a laboratory dataset with any of the commonly used equations for the SWCC (Fredlund et al. 2011). One means of circumventing this problem is to use a bimodal form of the Fredlund-Xing (1994) SWCC equation. The soilwater characteristic curve, SWCC, forms the basis for the estimation of various unsaturated soil property functions. Research has shown that the soil-water characteristic curve, SWCC, strongly influences the estimation of the permeability function for an unsaturated soil (Rahimi et al. 2015).

\section{Background on SWCC, shrinkage curve and permeability functions}

\section{Literature review on the role of the SWCC}

The SWCC describes the relationship between the amount of water in the soil and its corresponding soil suction, and the drying relationship differs from the wetting relationship (Tami et al. 2004). One of several variables can be used to designate the amount of water in the soil (e.g., gravimetric water content, volumetric water content and degree of saturation). The SWCC has become pivotal to the estimation of unsaturated soil property functions such as the permeability function and the water storage function (Fredlund et al. 2012). The direct measurement on the SWCC is a common practice in geotechnical engineering, providing a means of better understanding unsaturated soil properties. Much of the original laboratory testing equipment for measuring the SWCC was developed in the agricultural related disciplines. Laboratory equipment for measuring the SWCC can be broadly divided into equipment that provides an applied matric suction to a soil specimen and equipment that provides a controlled or measured total suction environment (Fredlund et al. 2012). The measured SWCC can be represented by a mathematical function and then used to determine the unsaturated soil 
property functions. A number of equations for SWCC have been proposed in the literature by various researchers.

The Brooks and Corey (1964) equation, the Gardner (1974) equation, various forms of the van Genuchten (1980) equation and the Fredlund-Xing (1994) equation appear to be the most commonly used SWCC equations in geotechnical engineering. The original van Genuchten (1980) is a 3-parameter equation that has the ability to best-fit data from a wide range of soils. The van Genuchten (1980) equation has been simplified by prescribing a fixed relationship between the $m$ and $n$ fitting parameters. The proposed simplification made it possible to obtain a closed-form permeability function for an unsaturated soil when substituting a simplified van Genuchten (1980) SWCC equation into the Burdine (1953) equation or the Mualem (1976) integral equation for the unsaturated permeability function. The simplified van Genuchten (1980) equations resulted in less mathematical flexibility than the original van Genuchten (1980) equation when best-fitting the experimental SWCC data. The Fredlund-Xing (1994) equation is a four-parameter equation that provides increased flexibility in fitting SWCC data over the complete range of soil suction values (i.e., up to 1,000,000 kPa). Leong and Rahardjo (1997) evaluated various proposed sigmoidal SWCC equations and identified the Fredlund-Xing (1994) equation as performing best for fitting all soil types.

Aforementioned sigmoidal SWCC equations are intended for unimodal SWCCs for soils that are well-graded with one dominant continuous series of pore sizes. When two or more pore series exist, the corresponding SWCC tends to be bimodal or multimodal (Zhang and Chen 2005). A modification to the fitting equation is required to properly represent the bimodal or multimodal SWCC for a gap-graded soil, where there is more than one pore series. Burger and Shackelford (2001a; 2001b) presented piecewise-continuous forms of the Brooks-Corey (1964), van Genuchten (1980), and Fredlund-Xing (1994) SWCC functions to account for the bimodal patterns of experimental SWCCs. The piecewise-continuous forms for the SWCC were tested on pelletized diatomaceous earth and sand-diatomaceous earth mixtures with dual porosity. 
Zhang and Chen (2005) proposed a method to predict bimodal or multimodal SWCCs for bimodal or multimodal soils using the unimodal SWCCs for the characteristic components corresponding to respective pore series.

\section{Literature review on the shrinkage curve}

The shrinkage curve establishes a relationship between the instantaneous void ratio and gravimetric water content. The shrinkage curve can play an important role in estimating unsaturated soil property functions for soils that exhibit significant volume change as soil suction is changed. Researchers have investigated the character of the shrinkage of soils since the early 1900s (Tempany 1917). An interpretation of the shrinkage curve was presented by Haines (1923) that included the concept of normal shrinkage and residual shrinkage. Terzaghi (1925) noted that the shrinkage behavior could be compared to the isotropic compression of a soil. Sridharan and Rao (1971) discussed the physical mechanism involved in the process of shrinkage using a modified effective stress concept. Kim et al. (1992) studied shrinkage processes and the geometry of volume shrinkage with respect to the physical ripening naturally occurring in a marine clay soil. Marinho (1994) carried out a comprehensive study of shrinkage curve functions. Fredlund (2000) presented a mathematical equation for the shrinkage curve as well as a theoretical procedure for estimating the shrinkage curve. Cornelis et al. (2006) proposed a simplified parametric model and assessed the magnitude and geometry of soil shrinkage. Some other relatively recent work that has been published on shrinkage of tailings is Rodriguez (2006) and Saleh-Mbemba et al. (2016). The Fredlund (2000) shrinkage equation accurately represents the shrinkage behavior for the drying of soils from a near-saturated state. The shrinkage curve equation proposed by Fredlund (2000) is used in this study as the basis for separating the effects of volume change and degree of saturation effects when estimating the permeability function for high volume change soils. 


\section{Literature review related to the permeability function}

Direct measurement of the permeability function of an unsaturated soil in the laboratory is timeconsuming, expensive and technically demanding. Measurements of the SWCC and the subsequent estimation of permeability functions have become the more common approach in geotechnical engineering for determining an acceptable permeability function (Zhang et al. 2016).

There are four main categories of models that have been proposed for the estimation of unsaturated permeability function; namely, empirical models, statistical models, correlation models and regression models (Leong and Rahardjo 1997; Fredlund et al. 2012). Empirical models and statistical models are most common. Empirical models estimate the unsaturated permeability function from the SWCC by utilizing the similarities between the SWCC and the unsaturated permeability function. The Brooks and Corey (1964) equation is one of the empirical estimation equations. Statistical models are based on the assumption that both the permeability function and the SWCC are primarily influenced by the pore-size distribution of the soil.

Childs and Collis-George (1950), Burdine (1953) and Mualem (1976) respectively proposed an integral formula for the estimation of the unsaturated permeability function based on different physical models. Various statistical models have been further developed from one of three integral formulas. The three well-known statistical models can be presented in the form of relative permeability equations and can be referred to as the van Genuchten-Burdine (1980) equation, the van Genuchten-Mualem (1980) equation and the Fredlund-Xing-Huang (1994) permeability function. These permeability equations were developed by introducing, i.) the van Genuchten SWCC (1980) equation into the Burdine (1953) formula, ii.) the van Genuchten SWCC (1980) equation into the Mualem (1976) formula, and iii.) the Fredlund-Xing SWCC equation (1994) into the Childs and Collis-George (1950) formula. A constant saturated coefficient of permeability is generally combined with the relative permeability functions to 
generate a continuous unsaturated soil permeability function. Historically, the estimation methods for these permeability functions have been based on the assumption that the soil does not undergo volume change as soil suction is increased.

Studies on deformable soils have been conducted for various purposes. Croney and Coleman (1954) measured soil suction and volume change for several compressible soils. Mbonimpa et al. (2006) proposed a model for the soil-water characteristic curve of deformable clayey soils by introducing the volumetric shrinkage curve in the formulation of the modified Kovacs (MK) model. Parent et al. (2007) conducted SWCC tests on "deinking by-product" (DBP), a highly compressible industrial by-product which has been used as a cover material for landfills and mining applications as well as a soil structural enhancement material in agricultural applications. Nuth and Laloui (2008) developed an innovative modeling framework for the SWCC based on kinematic hardening considering both capillary hysteresis and void ratio dependency. Tripathy et al. (2014) studied in detail the SWCCs of three deformable clays in terms of the water content and the degree of saturation. Huang et al. (1998) developed a coefficient of permeability model for a deformable unsaturated porous medium considering volume change prior to desaturation. Huang et al. (1998) suggested accounting for the effect of void ratio change on the saturated permeability, while the relative permeability was obtained using the volumetric water content SWCC ( $\theta$-SWCC). More recently, theoretical and previous experimental studies have been undertaken to observe the influence of both desaturation and volume change on the permeability function for deformable soils (Fredlund and Zhang 2013).

Existing methods are not adequate for estimating the permeability function for soils that undergo significant volume change both before and after the applied suction exceeds the air-entry value. It is necessary to develop a permeability function for a volume change soil that considers both the influence of volume change and desaturation during drying from saturation to oven-dry conditions. 
A revised methodology for estimating the permeability function for a soil that undergoes volume change during a drying process is presented in this paper.

\section{Modification to permeability function to integrate volume change General information on the permeability function theory}

The permeability theory is limited to using the soil-water characteristic curve in the case where significant volume changes occur as suction is increased. The SWCC has been used in a general sense to describe the amount of water in a soil as a function of soil suction. The designation for the amount of water in the soil defines the character of the SWCC. There are four different designations that have been used for defining the amount of water in a soil; namely, gravimetric water content $w$, volumetric water content (referenced to the initial total volume) $\theta$, instantaneous volumetric water content (referenced to the instantaneous total volume) $\theta_{\mathrm{i}}$ and degree of saturation $S$. However, volumetric water content referenced to the initial volume of soil has no value when considering the case of volume change with respect to suction change. Only the instantaneous volumetric water content is discussed in this paper and used for comparison with gravimetric water content and degree of saturation.

The SWCC can accordingly take on three different forms; namely, gravimetric water contentSWCC (w-SWCC), instantaneous volumetric water content-SWCC ( $\theta_{i}-$ SWCC), and degree of saturation-SWCC (S-SWCC). For soils that undergo insignificant volume change as soil suction is increased (e.g., sands and dense silts), all three SWCC designations provide the same information to geotechnical engineers for estimating unsaturated soil property functions. Figure 1 shows that the three SWCCs (i.e., $w$-SWCC, $\theta_{I}$ SWCC and S-SWCC) produce the same curve when plotted in terms of dimensionless water content versus soil suction. However, for a soil that undergoes volume change as soil suction is increased during a drying process, the three SWCCs are different from one another. Figure 2 presents the results of SWCC tests performed on oil sands tailings and shows that there is a difference amongst the $w$-SWCC, $\theta_{\Gamma}$ SWCC and 
S-SWCC. Oil sands tailings represents a material that undergoes significant volume change as soil suction is increased during drying.

Figure 1. Fredlund-Xing (1994) SWCC fit to experimental data for Columbia sandy silt (Data from Brooks and Corey (1964)).

Figure 2. Gravimetric water content, instantaneous volumetric water content and degree of saturation versus soil suction for thickened oil sands tailings tested

\section{Relationship between volume-mass variables}

Gravimetric water content constitutes the standard measurement used in the laboratory when performing a SWCC test. The degree of saturation and the instantaneous volumetric water content are indirectly calculated from the gravimetric water content measurements along with a shrinkage curve for the soil. The basic volume-mass relationships that relate the three designations of the amount of water in a soil are as below:

$$
\begin{gathered}
S=\frac{w G_{\mathrm{s}}}{e} \\
\theta_{\mathrm{i}}=\frac{S e}{1+e}=\frac{w G_{\mathrm{s}}}{1+e}
\end{gathered}
$$

The shrinkage curve test involves the measurement of volume and mass of water in the soil as drying occurs. This allows to describe the relationship between void ratio and gravimetric water content. The following hyperbolic equation proposed by Fredlund (2000) can be used to represent the shrinkage curve.

$$
e(w)=a_{\mathrm{sh}}\left(\left(\frac{w}{b_{\mathrm{sh}}}\right)^{c_{\mathrm{sh}}}+1\right)^{\frac{1}{c_{\mathrm{sh}}}}
$$

where: 
$a_{s h}=$ minimum void ratio, $e_{\min }$,

$a_{s h} / b_{s h}=$ slope of the asymptotic line,

$c_{s h}=$ curvature of the shrinkage curve, and

$a_{s h}, b_{s h}$ and $c_{s h}$ are three fitting parameters of the shrinkage equation Eq. [3], which can be obtained by a regression analysis. The Fredlund (2000) equation has the following relationship between the fitting parameters and the volume-mass properties.

$$
\frac{a_{\mathrm{sh}}}{b_{\mathrm{sh}}}=\frac{G_{\mathrm{s}}}{S_{0}}
$$

The equation forms a continuous function with $e(w)=\frac{a_{\mathrm{sh}}}{b_{\mathrm{sh}}} w$ as its asymptotic line. The shrinkage curve moves closer and closer to a straight asymptotic line of constant degree of saturation as gravimetric water content increases.

The shrinkage curve becomes an important mathematical relationship when solving geotechnical engineering problems where drying produces significant volume change. Eq. [3] is used as the basis for the development of a revised methodology for estimating the permeability function for high volume change materials.

\section{Various forms of SWCC}

The Fredlund-Xing (1994) equation has been used to provide a reasonable fit of SWCC laboratory data over the entire suction range. The SWCC equation, written in terms of gravimetric water content versus soil suction, is as follows.

$$
w(\psi)=\frac{w_{\mathrm{s}}\left(1-\ln \left(1+\psi / \psi_{\mathrm{r}}\right) / \ln \left(1+10^{6} / \psi_{\mathrm{r}}\right)\right)}{\left(\ln \left(\exp (1)+\left(\psi / a_{\mathrm{f}}\right)^{n_{\mathrm{f}}}\right)\right)^{m_{\mathrm{f}}}}
$$

where:

$a_{\mathrm{f}}, n_{\mathrm{f}}, m_{\mathrm{f}}$, and $\psi_{\mathrm{r}}=$ mathematical fitting parameters, 
Equation [5] is a sigmoidal equation that can be used to best-fit unimodal soil-water characteristics data. The large deformations associated with the oil sands tailings give the appearance of bimodal behavior and consequently it is also possible to more closely fit the data using a bimodal form for w-SWCC. Zhang and Chen (2005) presented a method for the determination of soil-water characteristic curves for soils with bimodal or multimodal pore-size distributions. The theoretical bimodal SWCC function developed by Zhang and Chen (2005) made use of the Fredlund and Xing (1994) function in the following manner:

$\theta(\psi)=p_{1} n_{\mathrm{pl}}\left(1-\frac{\ln \left(1+\frac{\psi}{\psi_{\mathrm{rl}}}\right)}{\ln \left(1+\frac{10^{6}}{\psi_{\mathrm{rl}}}\right)}\right)\left(\frac{1}{\ln \left(\exp (1)+\left(\frac{\psi}{a_{1}}\right)^{n_{1}}\right)}\right)^{m_{1}}+p_{s} n_{\mathrm{ps}}\left(1-\frac{\ln \left(1+\frac{\psi}{\psi_{\mathrm{rs}}}\right)}{\ln \left(1+\frac{10^{6}}{\psi_{\mathrm{rs}}}\right)}\right)\left(\frac{1}{\ln \left(\exp (1)+\left(\frac{\psi}{a_{s}}\right)^{n_{s}}\right)}\right)^{m_{s}}$

where,

$p_{1}$ and $p_{\mathrm{s}}=$, respectively, volumetric percentages of the components with the large-pore series and the small-pore series in the soil mass that can be calculated easily based on the density values and the percentages by dry weight of the soil components;

$n_{\mathrm{pl}}$ and $n_{\mathrm{ps}}=$ porosities of the components with the large-pore series and the small-pore series when they are considered individually.

$a_{1}, n_{1}, m_{1}, \psi_{\mathrm{rl}}$, and $a_{\mathrm{s}}, n_{\mathrm{s}}, m_{\mathrm{s}}, \psi_{\mathrm{rs}}=$ parameters of the SWCC function for the components with the large-pore series and the small-pore series.

The bimodal function is quite complex and contains many fitting parameters. Fitting the model to data can also result in variances in the estimated parameters for the same soil. In other words, a unique solution cannot be guaranteed. There will consequently be a greater dependency of the estimated model parameters on their initial estimates. It is also possible that the computer algorithm may become trapped within a local minimum. Although the bimodal model has a 
sound theoretical base, it is preferable to keep the SWCC expression as simple as possible. It should be noted that it is the mathematical form of analytical expressions that determines the accuracy of the estimated permeability function rather than the physical meaning of the fitting parameters as was demonstrated by Cornelis et al. (2006). On the other hand, empirical models have limitations when compared to the deterministic models that they do not allow for better understanding of the real process. The original theoretical bimodal equation by Zhang and Chen (2005) (Eq. [6]) has two correction functions. The role of the correction function is to bring the calculated water content to zero at the limiting point where $\psi$ is equal to $10^{6} \mathrm{kPa}$. Therefore, it is possible to use one correction function rather than two correction functions. In the original theoretical bimodal, there is a correlation between the fitting parameters as shown below:

$$
\theta_{\mathrm{s}}=p_{1} n_{\mathrm{pl}}+p_{\mathrm{s}} n_{\mathrm{ps}}
$$

Where:

$p_{1} n_{\mathrm{pl}}$ and $p_{\mathrm{s}} n_{\mathrm{ps}}$ are the saturated volumetric water content of each pore series, $p_{\mathrm{l}} n_{\mathrm{pl}}$ and $p_{\mathrm{s}} n_{\mathrm{ps}}$ denotes the proportions of two pore series.

A weighting factor $p$ between 0 and 1.0 can be used to represent the proportion of the large pore series, and 1-p the small pore series. The saturated volumetric water content of the large pore series is $\theta_{\mathrm{s}} p$, which is represented by $p_{\mathrm{l}} n_{\mathrm{pl}}$. The saturated volumetric water content of the small pore series is $\theta_{\mathrm{s}}(1-p)$, which is represented by $p_{\mathrm{s}} n_{\mathrm{ps}}$. It is possible to use a simplified bimodal equation to that proposed by Zhang and Chen (2005). The simplified bimodal equation written in terms of gravimetric water content versus soil suction is.

$$
w(\psi)=w_{\mathrm{s}}\left(1-\frac{\ln \left(1+\frac{\psi}{\psi_{\mathrm{rb}}}\right)}{\ln \left(1+\frac{10^{6}}{\psi_{\mathrm{rb}}}\right)}\right)\left(\frac{p}{\left(\ln \left(\exp (1)+\left(\frac{\psi}{a_{\mathrm{f} 1}}\right)^{n_{\mathrm{f} 1}}\right)\right)^{m_{\mathrm{fl}}}}+\frac{1-p}{\left(\ln \left(\exp (1)+\left(\frac{\psi}{a_{\mathrm{f} 2}}\right)^{n_{\mathrm{f} 2}}\right)\right)^{m_{\mathrm{f} 2}}}\right)
$$

where: 
$a_{\mathrm{f} 1}, n_{\mathrm{f} 1}, m_{\mathrm{f} 1}, a_{\mathrm{f} 2}, n_{\mathrm{f} 2}, m_{\mathrm{f} 2}$, and $\psi_{\mathrm{rb}}=$ mathematical fitting parameters, $p=$ a weighting factor between 0 to 1.0 used to divide the bimodal behavior,

The simplified bimodal model (Eq. [8]) is used to best-fit the bimodal measured w-SWCC data, while the Fredlund-Xing (1994) equation, (i.e., Eq. [5]) is recommended to best-fit the unimodal measured $w$-SWCC data. The $\theta_{\mathrm{i}}$-SWCC and S-SWCC functions can be obtained by combining the best-fit $w$-SWCC with the Fredlund (2000) shrinkage curve equation. The simplified bimodal equation (Eq. [8]) is used for handling the bimodal behavior and to develop the revised methodology for estimating the permeability function. The revised procedure for estimating the permeability function of a high-volume-change soil with a unimodal $w$-SWCC is outlined in Appendix A.

A relationship of void ratio versus soil suction can be obtained by substituting Eq. [8] into Eq. [3]. $\left.e(\psi)=a_{\mathrm{sh}}\left(\frac{w_{\mathrm{s}}}{b_{\mathrm{sh}}}\left(1-\frac{\ln \left(1+\frac{\psi}{\psi_{\mathrm{rb}}}\right)}{\ln \left(1+\frac{10^{6}}{\psi_{\mathrm{rb}}}\right)}\right)\left(\frac{p}{\left(\ln \left(\exp (1)+\left(\frac{\psi}{a_{\mathrm{f} 1}}\right)^{n_{\mathrm{fl}}}\right)\right)^{m_{\mathrm{fl}}}}+\frac{1-p}{\left(\ln \left(\exp (1)+\left(\frac{\psi}{a_{\mathrm{f} 2}}\right)^{n_{\mathrm{f} 2}}\right)\right)^{m_{\mathrm{f} 2}}}\right)\right)^{)^{\frac{1}{c_{\mathrm{sh}}}}}+1\right)^{\frac{c_{\mathrm{sh}}}{}}$

Substituting Eq. [8] and Eq. [9] into the basic volume-mass relationships, (i.e., Eqs. [1] and [2]), leads to the best-fitting equations for S-SWCC and $\theta_{i}-$ SWCC, as shown in Eqs. [10] and [11], respectively. 


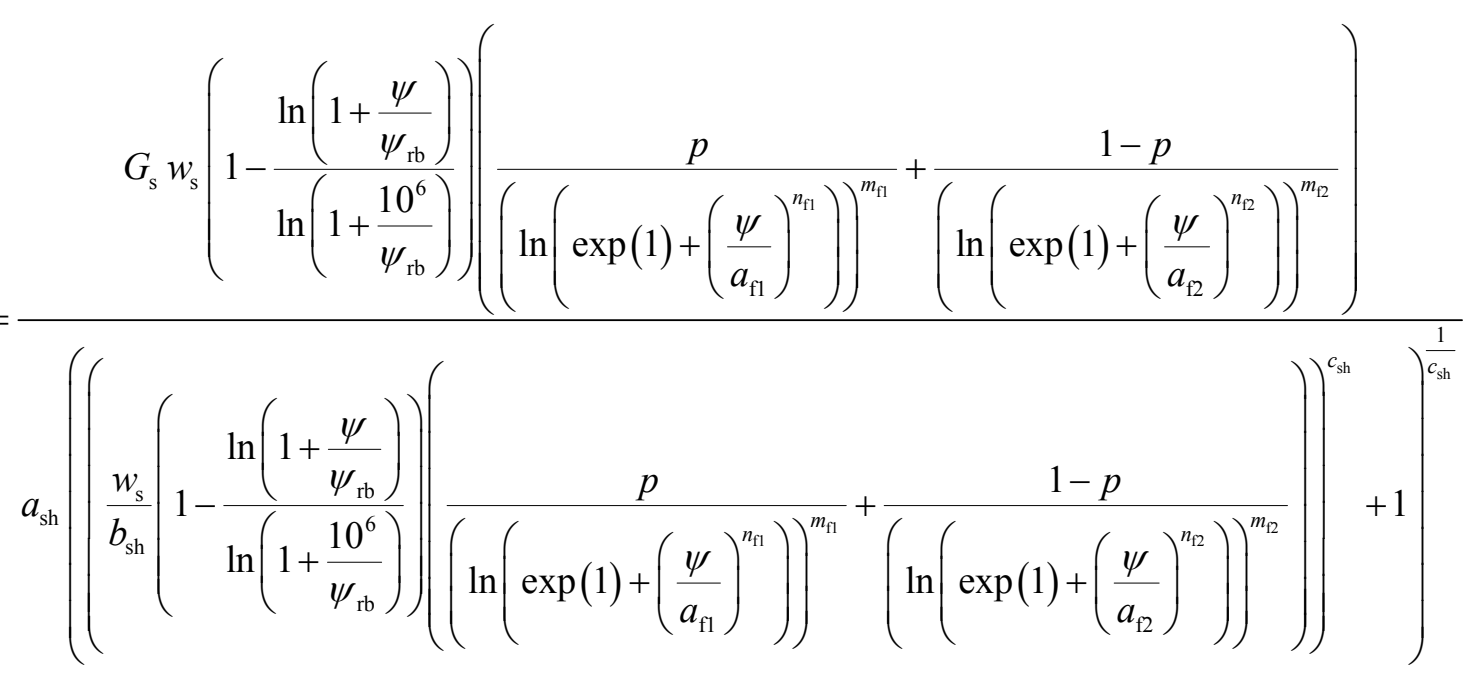

$$
\begin{aligned}
& S(\psi)= \\
& \theta_{\mathrm{i}}(\psi)= \\
& G_{\mathrm{s}} w_{\mathrm{s}}\left(1-\frac{\ln \left(1+\frac{\psi}{\psi_{\mathrm{rb}}}\right)}{\ln \left(1+\frac{10^{6}}{\psi_{\mathrm{rb}}}\right)}\right)\left(\frac{p}{\left(\ln \left(\exp (1)+\left(\frac{\psi}{a_{\mathrm{f} 1}}\right)^{n_{\mathrm{fl}}}\right)\right)^{m_{\mathrm{fl}}}}+\frac{1-p}{\left(\ln \left(\exp (1)+\left(\frac{\psi}{a_{\mathrm{f} 2}}\right)^{n_{\mathrm{r} 2}}\right)\right)^{m_{\mathrm{r} 2}}}\right) \\
& 1+a_{\mathrm{sh}}\left(\left(\frac{w_{\mathrm{s}}}{b_{\mathrm{sh}}}\left(1-\frac{\ln \left(1+\frac{\psi}{\psi_{\mathrm{rb}}}\right)}{\ln \left(1+\frac{10^{6}}{\psi_{\mathrm{rb}}}\right)}\right)\left(\frac{p}{\left(\ln \left(\exp (1)+\left(\frac{\psi}{a_{\mathrm{fl}}}\right)^{n_{\mathrm{fl}}}\right)\right)^{m_{\mathrm{fl}}}}+\frac{1-p}{\left(\ln \left(\exp (1)+\left(\frac{\psi}{a_{\mathrm{f} 2}}\right)^{n_{\mathrm{r} 2}}\right)\right)^{m_{\mathrm{f} 2}}}\right)\right)^{)^{c_{\mathrm{sh}}}}+1\right)^{\frac{1}{c_{\mathrm{sh}}}}
\end{aligned}
$$

Equations [9] to [11] are changed in response to the best-fit equations used for the w-SWCC and the shrinkage curve. Improved fitting of the $w$-SWCC results in improved fitting of the $S$ SWCC and the $\theta_{\mathrm{i}}$-SWCC. Laboratory oil sands tailings measurements are used for illustration and verification purposes.

The degree of saturation SWCC (S-SWCC), should be used to determine the relative permeability function and the correct air-entry value, $A E V$, which forms the starting point for 
integration for the relative permeability function (Zhang and Fredlund 2015; Fredlund and Zhang 2013). Likewise, the $\theta_{i}-$ SWCC should be used for the calculation of the water storage function. Misuse of SWCCs when estimating unsaturated soil property functions can result in significant errors. Demonstration of the importance of using the appropriate form of SWCC is presented later in the paper.

\section{Revised methodology for estimating the permeability function}

The proposed methodology for the estimation of the permeability function for soils undergoing large volume changes is presented in the following section. The permeability at a particular suction during a drying process is the product of the relative permeability and the corresponding saturated permeability of the soil as shown in Eq. [12].

$$
k(\psi)=k_{\mathrm{r}}(\psi) \times k_{\mathrm{rs}}(\psi)
$$

where:

$k(\psi)=$ permeability at a particular soil suction, $\psi$,

$k_{\mathrm{r}}(\psi)=$ relative permeability at the soil suction, $\psi$, and

$k_{\mathrm{rs}}(\psi)=$ reference saturated permeability at the soil suction of $\psi$.

The reference saturated permeability corresponds to the saturated permeability when the soil at a particular suction is in single-phase water flow.

The degree of saturation and the void ratio are two controlling factors that influence the computed permeability function. The effect of degree of saturation is considered in the relative permeability function, $k_{\mathrm{r}}(\psi)$ while the influence of the void ratio is included in the reference saturated permeability function, $k_{\mathrm{rs}}(\psi)$. Changes in the degree of saturation change the tortuosity of the flow path within the porous media. The tortuosity, in turn, changes the relative permeability (Fredlund et al. 2012). The saturated permeability of a soil depends mainly on, fluid 
properties, the pore sizes and the pore size distribution (Chapuis 2012). A change in void ratio changes the pore sizes, thereby influencing the reference saturated permeability of the soil.

The two components in Eq. [12], $k_{\mathrm{r}}(\psi)$ and $k_{\mathrm{rs}}(\psi)$ can be separately calculated. The relative permeability function, $k_{r}(\psi)$ is estimated from the S-SWCC. The reference saturated permeability function, $k_{\mathrm{rs}}(\psi)$ is calculated based on two relationships, the relationship of void ratio versus soil suction and the relationship of saturated permeability versus void ratio. Studies on the relationship between the void ratio and the saturated permeability of a soil have been undertaken by numerous researchers (Chapuis 2012). Equation [13] (Taylor 1948) and Eq. [14] (Somogyi 1980) are two mathematical equations that describe the relationship of the saturated coefficient of permeability, $k_{\text {sat }}$, to void ratio, $e$.

$$
\begin{gathered}
k_{\text {sat }}(e)=\frac{C e^{x}}{1+e} \\
k_{\text {sat }}(e)=A e^{B}
\end{gathered}
$$

where:

$k_{\text {sat }}=$ saturated permeability,

$C, x=$ fitting parameters for Eq. [13], and

$A, B=$ fitting parameters for Eq. [14].

Each of these equations (i.e., Eqs. [13] and [14]) can be used in conjunction with the relationship between void ratio and soil suction (Eq. [9]) to generate the reference saturated permeability function, $k_{\mathrm{rs}}(\psi)$. Equation [14] is used in this paper to illustrate how to obtain the reference saturated permeability function, $k_{\mathrm{rs}}(\psi)$. By substituting Eq. [9] into Eq. [14], the term of the reference saturated permeability function, $k_{\mathrm{rs}}(\psi)$ in Eq. [12] can be obtained, as shown by Eq. [15]. 


$$
\begin{aligned}
& k_{\mathrm{rs}}(\psi)= \\
& A\left(a_{\mathrm{sh}}\left(\left(\frac{w_{\mathrm{s}}}{b_{\mathrm{sh}}}\left(1-\frac{\ln \left(1+\frac{\psi}{\psi_{\mathrm{rb}}}\right)}{\ln \left(1+\frac{10^{6}}{\psi_{\mathrm{rb}}}\right)}\right)\left(\frac{p}{\left(\ln \left(\exp (1)+\left(\frac{\psi}{a_{\mathrm{f} 1}}\right)^{n_{\mathrm{fl}}}\right)\right)^{m_{\mathrm{fl}}}}+\frac{1-p}{\left(\ln \left(\exp (1)+\left(\frac{\psi}{a_{\mathrm{f} 2}}\right)^{n_{\mathrm{f}}}\right)\right)^{m_{\mathrm{f} 2}}}\right)\right)^{m^{c_{\mathrm{sh}}}}+1\right)^{\frac{1}{\mathrm{sh}}^{c_{\mathrm{sh}}}}\right)^{B}
\end{aligned}
$$

Considerable research has also been undertaken on the estimation of the relative permeability function. Its prediction is usually based on the volumetric water content SWCC ( $\theta$-SWCC) under the assumption of no volume change during a drying process. The original Fredlund-XingHuang (1994) permeability function takes the following form:

$$
k_{\mathrm{r}}(\psi)=\frac{\int_{\ln (\psi)}^{\mathrm{b}} \frac{\theta\left(e^{y}\right)-\theta(\psi)}{e^{y}} \theta^{\prime}\left(e^{y}\right) d y}{\int_{\ln \left(\psi_{\text {aev }}\right)}^{b} \frac{\theta\left(e^{y}\right)-\theta\left(\psi_{\text {aev }}\right)}{e^{y}} \theta^{\prime}\left(e^{y}\right) d y}
$$

where:

$b=\ln (1,000,000)$, and

$y=$ a dummy variable of integration representing the logarithm of soil suction.

The original Fredlund-Xing-Huang (1994) permeability function produces appropriate relative permeability estimations for no volume change materials such as sands or silts because the $\theta$ SWCC provides essentially the same information as the S-SWCC when there is no volume change. When a soil undergoes volume change, the degree of saturation SWCC, (S-SWCC) should be used to estimate the relative permeability function. Therefore, the Fredlund-XingHuang (1994) permeability function should be modified and the S-SWCC used for estimation purposes: 


$$
k_{\mathrm{r}}^{s}(\psi)=\frac{\int_{\ln (\psi)}^{\mathrm{b}} \frac{S\left(e^{y}\right)-S(\psi)}{e^{y}} S^{\prime}\left(e^{y}\right) d y}{\int_{\ln \left(\psi_{\text {aev }}\right)}^{b} \frac{S\left(e^{y}\right)-S\left(\psi_{\text {aev }}\right)}{e^{y}} S^{\prime}\left(e^{y}\right) d y}
$$

where:

$k_{r}^{s}=$ the relative coefficient of permeability and the superscript " $\mathrm{s}$ " denotes that the S-SWCC is used as the basis for the permeability estimation.

A different relative permeability function is obtained when using different forms of SWCC as the basis for calculating the permeability functions. The following two equations (i.e., Eqs [18] and [19]) are based on the $w$-SWCC and the $\theta_{i}$-SWCC and are used in the following section to illustrate the errors that can occur when the wrong SWCC designations are used. The correct equation to use is Eq. [17] when estimating the unsaturated permeability function. It should also be noted that the AEV should be used as the lower limit of integration for the integral in the denominator (Zhang and Fredlund 2015).

$$
k_{\mathrm{r}}^{\omega}(\psi)=\frac{\int_{\ln (\psi)}^{\mathrm{b}} \frac{w\left(e^{y}\right)-w(\psi)}{e^{y}} w^{\prime}\left(e^{y}\right) d y}{\int_{\ln \left(\psi_{\mathrm{aev}}\right)}^{b} \frac{w\left(e^{y}\right)-w\left(\psi_{\mathrm{aev}}\right)}{e^{y}} w^{\prime}\left(e^{y}\right) d y}
$$

where:

$k_{\mathrm{r}}{ }^{w}=$ the relative coefficient of permeability with the superscript " $w$ " denoting that the $w$-SWCC is used as the basis for calculating the permeability function.

$$
k_{\mathrm{r}}^{\theta_{\mathrm{i}}}(\psi)=\frac{\int_{\ln (\psi)}^{\mathrm{b}} \frac{\theta_{\mathrm{i}}\left(e^{y}\right)-\theta_{\mathrm{i}}(\psi)}{e^{y}} \theta_{\mathrm{i}}^{\prime}\left(e^{y}\right) d y}{\int_{\ln \left(\psi_{\text {aev }}\right)}^{b} \frac{\theta_{i}\left(e^{y}\right)-\theta_{i}\left(\psi_{\text {aev }}\right)}{e^{y}} \theta_{\mathrm{i}}^{\prime}\left(e^{y}\right) d y}
$$


where:

$k_{\mathrm{r}}^{\theta i}=$ the relative coefficient of permeability with the superscript $\theta_{\mathrm{i}}$ denoting that the $\theta_{\mathrm{i}}$-SWCC is used as the basis for the permeability function.

S-SWCC best-fitted by Eq. [10] is suggested to be used in the $k_{\mathrm{r}}^{s}(\psi)$ function for the estimation of the relative permeability function of a high-volume-change soil with bimodal w-SWCC such as oil sands tailings. For a high-volume-change soil with unimodal w-SWCC such as Regina clay, S-SWCC best-fitted by Eq. [A-5] in the Appendix A can be used in the $k_{\mathrm{r}}^{s}(\psi)$ function for the estimation of the relative permeability function.

The overall permeability function for a high-volume-change material can be determined by multiplying the reference saturated permeability function by the relative permeability function as shown in Eq. [12]. By substituting the $k_{\mathrm{r}}^{s}(\psi)$ function (Eq. [17]) and Eq. [15] into Eq. [12], a function can be obtained for the estimation of the permeability function for a soil that undergoes volume change as soil suction changes during a drying process. The simplified form of the computed permeability function is shown as Eq. [20].

$$
k(\psi)=\frac{A(e(\psi))^{B} \int_{\ln (\psi)}^{\mathrm{b}} \frac{S\left(e^{y}\right)-S(\psi)}{e^{y}} S^{\prime}\left(e^{y}\right) d y}{\int_{\ln \left(\psi_{\mathrm{aev}}\right)}^{b} \frac{S\left(e^{y}\right)-S\left(\psi_{\mathrm{aev}}\right)}{e^{y}} S^{\prime}\left(e^{y}\right) d y}
$$

The fitting parameters in Eq. [20] are obtained from the shrinkage curve, (i.e., Eq. [3]), the wSWCC, (i.e., Eq. [8]) and the best-fitting curve for the relationship of the saturated permeability versus the void ratio, (i.e., Eq. [14]). Equation [20] changes when the best-fitting equation for the w-SWCC changes. An appropriate best-fitting curve for $w$-SWCC is important for obtaining a desirable permeability function using Eq. [20]. Equation [5] is recommended for best-fitting unimodal measured $w$-SWCC data while Eq. [8] is suggested to best-fit bimodal measured $w$ SWCC data. Both Equations [5] and [8] are used to best-fit $w$-SWCC and estimate the relative 
permeability function for oil sands tailings for comparison. The steps for estimating the permeability function of a soil exhibiting unimodal $w$-SWCC that changes volume as soil suction increases are presented with the corresponding equations in Appendix A.

\section{Application of the modified permeability function to oil sands tailings \\ Experimental data for oil sands tailings}

The experimental data used for analysis purposes were previously published by Fredlund et al. (2011). The data was part of a research study undertaken for the oil company, TOTAL. An experimental procedure was developed to measure the entire shrinkage curve for a soil. Each soil specimen was prepared at high water contents in a slurry state and placed into shrinkage rings and allowed to slowly dry by exposure to air. Rings (brass rings) with no bottom were used to contain each soil specimen. The rings with the soil were placed onto wax paper and drying was commenced. The dimensions of rings were selected such that cracking of the soil was unlikely to occur during the drying process. The ring dimensions selected for the shrinkage curve specimens had a diameter of $3.7 \mathrm{~cm}$ and a thickness of $1.2 \mathrm{~cm}$.

The mass and volume of each soil specimen were measured on a daily basis. A digital micrometer was used to measure the volume of the specimen at various stages of drying. Four to six measurements of the diameter and thickness of the specimen were made at different locations on the specimens. Figure 3 shows typical measurements of water content and void ratio as the soil dried. It was observed that as the specimen diameter began to decrease, with the specimen pulling away from the brass ring, the rate of evaporation increased significantly. The increase in the evaporation rate was related to the increased surface area from which evaporation was occurring. Consequently, it is recommended that the measurements of mass and volume should be increased to once every two to three hours once the soil shows signs of pulling away from the sides of the ring. 
Figure 3. Shrinkage curve for thickened oil sands tailings

The SWCC test is an important laboratory test conducted to determine the relationship between soil suction and the amount of water in the soil. The measured soil-water characteristic curve is usually plotted as gravimetric water content versus soil suction. Pressure plate cells and desiccators with saturated salt solutions were used to measure the SWCC over the entire range of suctions. Small pressure cells were used to apply suctions in the range from 0 to $400 \mathrm{kPa}$ and controlled relative humidity cells were used for suctions from 4,000 kPa to $300,000 \mathrm{kPa}$, using various salt solutions.

The experimental data is used to test the proposed theory for the estimation of the permeability function. The oil sands tailings results presented are for thickened tailings with a sand-to-fine ratio (SFR) of 0.8 (Fredlund et al. 2011). The oil sands thickened tailings had a liquid limit of $35 \%$ and a plastic limit of $15 \%$. The shrinkage curve and the soil-water characteristic curves were measured. The shrinkage curve results are presented in Figure 3. The best-fitting parameters of the shrinkage curve for the oil sands tailings are, $a_{\mathrm{sh}}=0.394, b_{\mathrm{sh}}=0.162$, and $c_{\mathrm{sh}}=3.208$. The average specific gravity $\left(G_{s}\right)$ was 2.43 . The gravimetric water content, $w$, plotted versus soil suction for oil sands tailings is shown in Figure 4. The oil sands w-SWCC data are best-fit using both of the Fredlund-Xing (1994) unimodal equation (Eq. [5]) and the simplified bimodal wSWCC equation (Eq. [8]) for the purpose of comparison. The best-fit parameters of the Fredlund-Xing (1994) equation are $a_{\mathrm{f}}=1.250 \mathrm{kPa}, n_{\mathrm{f}}=0.982, m_{\mathrm{f}}=0.612$, and $\psi_{\mathrm{r}}=107.4 \mathrm{kPa}$. The best-fit parameters of the simplified bimodal equation are $a_{\mathrm{f} 1}=0.306 \mathrm{kPa}, a_{\mathfrak{f} 2}=10355 \mathrm{kPa}$, $n_{\mathrm{f} 1}=1.181, n_{\mathrm{f} 2}=0.946, m_{\mathrm{f} 1}=0.794, m_{\mathrm{f} 2}=35.773$ and $\psi_{\mathrm{rb}}=1.875 \mathrm{kPa}, p=0.767$. The initial gravimetric water content was $73.8 \%$. The measured $w$-SWCC data for the thickened oil sands tailings display a bimodal feature as shown in Figure 4. Thus, the best-fitting curve obtained by the simplified bimodal equation (Eq. [8]) represents the measured data points more closely than the best-fitting curve obtained by the unimodal Fredlund-Xing (1994) equation as shown in Figure 4. The $w$-SWCC is used in conjunction with the shrinkage curve to calculate S-SWCC 
and $\theta_{\mathrm{i}}$-SWCC. The quality of the fitting of the $w$-SWCC can influence the closeness of the fitting of the subsequent other forms of SWCCs (i.e., $\theta_{i}$-SWCC and S-SWCC).

Figure 4. Gravimetric water content versus soil suction for thickened oil sands tailings.

The relationship between the saturated coefficient of permeability and void ratio was also measured in the laboratory by constant head tests. Constant head tests were conducted on 100 $\mathrm{mm}$ diameter samples in a modified Proctor mould. A constant head hydraulic gradient was applied across the sample, and the outflow of water was measured and recorded. The experimental data were best-fitted using Eq. [14]. Figure 5 shows the measured results and the best-fitting curve. Equation [14] produces a reasonable fitting curve for the saturated permeability versus void ratio relationship for thickened oil sands tailings with the fitting parameters $A=1.263 \times 10^{-9}$ and $B=3.042$.

The shrinkage curve (Figure 3), the w-SWCC (Figure 4) and the curve of saturated permeability versus void ratio (Figure 5), form the basis for the subsequent calculation for the permeability function for thickened oil sands tailings.

Figure 5. Measured data of saturated permeability versus void ratio and its best-fitting curves for thickened oil sands tailings

\section{Interpretation of the experimental data}

The gravimetric water content SWCC, $(w$-SWCC) is combined with the shrinkage curve to obtain the S-SWCC and $\theta_{i}$-SWCC (i.e., Eq. [10] and Eq. [11]). Figure 6 shows a relationship of the void ratio versus soil suction, which is calculated from the w-SWCC and the shrinkage curve. 
The resulting plot of degree of saturation versus soil suction is shown in Figure 7. The plot of $\theta_{\mathrm{i}}$ SWCC is shown in Figure 8. The dash fitting curves on Figures 6 to 8 are calculated on the basis of the fitting curve for the w-SWCC obtained using the simplified bimodal Eq. [8]. The solid fitting curves on Figures 6 to 8 are obtained using w-SWCC best-fitted by the unimodal Eq. [5]. The dash lines are closer fits to the data than the solid lines for the relationship between void ratio and soil suction, S-SWCC and $\theta_{\mathrm{i}}$-SWCC. Plots of Figures 6 to 8 illustrate the superior fit that can be obtained as a consequence of a better fit of the w-SWCC.

Figure 6. Void ratio versus soil suction for thickened oil sands tailings.

Figure 7. Degree of saturation versus soil suction for thickened oil sands tailings.

Figure 8. Instantaneous volumetric water content versus soil suction for thickened oil sands tailings.

The best-fit curves for the SWCCs obtained using the simplified bimodal equation for the $w$ SWCC are used to illustrate the importance of applying the correct form of SWCC in the estimation of the correct air-entry value and the relative permeability function. Table 1 lists the breaking points on various SWCCs. The breaking point along a SWCC is the matric suction at which the curve starts to bend down. The breaking point on the S-SWCC is called air-entry value, the matric suction where air starts to enter the largest pores in the soil. Breaking points are obtained by finding the point of intersection of two straight lines. One is the horizontal line passing the maximum water content, while the other line is the steepest slope line passing the first inflection point on the SWCC. For soils that undergo large volume changes such as thickened oil sands tailings, the breaking points on different SWCCs appear at different soil suctions (Table 1). The breaking point on the $w$-SWCC is at a soil suction of $0.113 \mathrm{kPa}$. The 
breaking point on the S-SWCC is at a soil suction of $111 \mathrm{kPa}$. The breaking point on the $\theta_{\mathrm{i}}$ SWCC is at a soil suction of $0.183 \mathrm{kPa}$. The air-entry value, AEV, of the soil must be estimated from the S-SWCC. The degree of saturation versus soil suction plot (Figure 7) indicates that the AEV is $111 \mathrm{kPa}$.

The relative permeability function is an important component constituting the permeability function for a soil that undergoes volume change as soil suction changes. Different permeability functions are obtained when using different forms of SWCC for estimation. Figure 9 shows three curves of the relative permeability function obtained respectively from $w$-SWCC, $\theta_{\mathrm{i}}$-SWCC, and S-SWCC. These three curves are obtained using Eqs. [17] to [19]. Soil suction at the breaking point on each SWCC was used as the lower limit of integration for the integral in the denominator of each estimation equation. The correct estimation of the relative permeability is the one obtained from the S-SWCC. Figure 9 shows that the results obtained from the $w$-SWCC under-estimated the relative permeability by 6.38 orders of magnitude, while the results obtained from the $\theta_{\mathrm{i}}$-SWCC under-estimated the relative permeability by 5.07 orders of magnitude. The differences shown in Figure 9 are substantial.

Figure 9. Relative permeability versus soil suction for thickened oil sands tailings.

Figure 10 illustrate the importance of the AEV when estimating the relative permeability function. The results show that the relative permeability versus soil suction obtained from S-SWCC differs when different values are used for the lower limit of integration. Table 2 presents the difference that could result when using a smaller value as the lower limit of integration. The difference in the resulting estimation for the relative permeability caused by using a lower limit of integration different than the AEV is significant (Zhang and Fredlund 2015). The $k_{\mathrm{r}}^{s}(\psi)$ function (Eq. [17]) specifies that the AEV should be used as the lower limit of integration for the integral in the 
denominator of the equation. The most reasonable curve for the relative permeability function is the one obtained when using the AEV as the lower limit of integration.

Figure 10. Relative permeability versus soil suction obtained from S-SWCC using different lower limits of integration for thickened oil sands tailings.

The quality of the best-fit for the S-SWCC also influences the correctness of the estimation results of the relative coefficient of permeability (Figure 11). Two curves of the relative coefficient of permeability in Figure 11 are estimated respectively from the two best-fitting curves of the S-SWCCs shown in Figure 7. The difference between two relative permeability curves at an AEV of $111 \mathrm{kPa}$ is about 1.13 orders of magnitude. A superior fitting of the $\mathrm{S}$ SWCC results in a more accurate estimation of the AEV and subsequently the relative permeability function. In the case of thickened oil sands tailings, the data are more closely fit when using the simplified bimodal $w$-SWCC equation and the corresponding subsequent forms of SWCCs. The AEV obtained from the S-SWCC best-fitted by the Eq. [A-5] is $33.2 \mathrm{kPa}$. The more accurate AEV is $111 \mathrm{kPa}$, the value obtained from the S-SWCC best-fitted by Eq. [10] (Figure 7). Eq. [10] is derived from the simplified bimodal $w$-SWCC equation, while Eq. [A-5] is derived from the unimodal Fredlund and Xing (1994) w-SWCC equation.

Figure 11. Relative permeability versus soil suction obtained from two best-fitting S-SWCCs for thickened oil sands tailings.

Figure 12. Relative permeability versus soil suction for thickened oil sands tailings. 
Figure 12 shows the curve of the relative permeability versus soil suction obtained when using the superior fit of the S-SWCC and the AEV as the lower limit of integration. The curve shown in Figure 12 is used for the subsequent calculation of the permeability function with Eq. [12].

The saturated permeability is a function of void ratio as shown in Figure 5. Equation [14] is used to best-fit the measured data to obtain the mathematical relationship between the saturated permeability and the void ratio. The void ratio changes with soil suction during the drying process as shown in Figure 6. The relationship of the void ratio and soil suction can be represented by Eq. [9]. As a result, the saturated permeability can be related to soil suction. When the saturated permeability is related to soil suction, it is referred to the reference saturated permeability. The reference saturated permeability is the corresponding saturated permeability related to the void ratio at a particular soil suction as shown in Figure 13. The reference saturated permeability versus soil suction is mathematically represented by Eq. [15].

Figure 13. Reference saturated permeability versus soil suction for thickened oil sands tailings.

After obtaining the relative permeability function shown in Figure 12 and the reference saturated permeability function shown in Figure 13, the coefficient of permeability function can be obtained by multiplying the relative permeability function by the reference saturated permeability function in accordance with Eq. [12]. The relationship of the coefficient of permeability to soil suction for thickened oil sands tailings is shown in Figure 14.

Figure 14. Coefficient of permeability versus soil suction for thickened oil sands tailings.

\section{Conclusions}

The void ratio and the degree of saturation are variables that influence the coefficient of permeability for a soil. Only the degree of saturation affects the coefficient of permeability when the soil does not change volume during a drying process. This paper presents a revised 
methodology for the estimation of the coefficient of permeability for a drying soil where both void ratio and degree of saturation change with soil suction. The proposed permeability function is the product of the reference saturated permeability function and the relative permeability function.

The effect of a change in void ratio on the coefficient of permeability function is presented as the reference saturated permeability function. The reference saturated permeability is the saturated permeability corresponding to a particular void ratio. The influence of a change in the degree of saturation is presented as a relative permeability function. The relative coefficient of permeability and the AEV should be estimated from the S-SWCC. The AEV should be used as the lower limit of integration in the integral of the denominator in the proposed permeability equation. Using other forms of the SWCC or other values as the lower limit of integration can lead to large estimation errors for the permeability function.

The quality of the fit of the S-SWCC affects the quality of the estimated permeability function. A superior fitting of the S-SWCC results in a more accurate estimation of the relative permeability function. The laboratory data for thickened oil sands tailings illustrate the detailed calculation procedure associated with the estimation of the coefficient of permeability function. The measured $w$-SWCC of thickened oil sands tailings exhibited a bimodal feature. A simplified bimodal $w$-SWCC equation was proposed and used to obtain a close fit for the $w$-SWCC. The shrinkage curve, the gravimetric water content versus soil suction and the saturated permeability versus void ratio are three basic experimental measurements required for the estimation of the coefficient of permeability function for soils that undergo volume change as soil suction is increased.

\section{Acknowledgements}

The authors want to acknowledge to contribution of TOTAL in support of the study that provided the laboratory test results that gave rise to the detailed analysis of the oil sands tailings material. 
The sponsorship of this study has led to improvements in the estimation of nonlinear soil property functions for large strain modeling of high volume change materials such as oil sands tailings.

\section{References}

BGC Engineering Inc. 2010. Oil sands tailings technology review (OSRIN Report No. TR-1). Retrieved from http://hdl.handle.net/10402/era.17555

Brooks, R.H., and Corey, A.T. 1964. Hydraulic properties of porous media. Hydrology Paper 3, Civil Engineering Department, Colorado State University, Fort Collins, CO.

Burdine, N. 1953. Relative permeability calculations from pore size distribution data. Journal of Petroleum Technology, 5 (03): 71-78.

Burger, C.A., and Shackelford, C.D. 2001a. Evaluating dual porosity of pelletized diatomaceous earth using bimodal soil-water characteristic curve functions. Can. Geotech. J., 38(1): 53-66.

Burger, C.A., and Shackelford, C.D. 2001b. Soil-water characteristic curves and dual porosity of sand-diatomaceous earth mixtures. J. Geotech. Geoenviron. Eng., 127(9): 790-800.

Chapuis, R.P. 2012. Predicting the saturated hydraulic conductivity of soils: a review. Bulletin of Engineering Geology and the Environment, 71(3): 401-434.

Childs, E.C., and Collis-George, N. 1950. The permeability of porous materials. In Proceedings of the Royal Society of London A: Mathematical, Physical and Engineering Sciences. The Royal Society, 201(1066): 392-405.

Cornelis, W. M., Corluy, J., Medina, H., Hartmann, R., Van Meirvenne, M., and Ruiz, M. E. 2006. A simplified parametric model to describe the magnitude and geometry of soil shrinkage. European Journal of Soil Science, 57(2): 258-268.

Croney, D., and Coleman, J. D. 1954. Soil structure in relation to soil suction (pF). Journal of Soil Science, 5(1): 75-84. 
Fredlund, D.G., and Xing, A. 1994. Equations for the soil-water characteristic curve. Canadian geotechnical journal, 31(4): 521-532.

Fredlund, D.G., Xing, A. and Huang, S. 1994. Predicting the permeability function for unsaturated soils using the soil-water characteristic curve. Canadian Geotechnical Journal, 31(4): 533-546.

Fredlund, D.G., Stone, J., Stianson, J., and Sedgwick, A. 2011. Determination of water storage and permeability functions for oil sands tailings. Proceedings of the $15^{\text {th }}$ International Conference on Tailings and Mine Waste, Vancouver, BC, Canada, November $6^{\text {th }}$ to $9^{\text {th }}, 2011$.

Fredlund, D.G., Rahardjo, H., and Fredlund, M.D. 2012. Unsaturated soil mechanics in engineering practice. John Wiley \& Sons, New York.

Fredlund, D.G., and Zhang, F-X. 2013. Combination of shrinkage curve and soil-water characteristic curves for soils that undergo volume change as soil suction is increased. Proceedings of the $18^{\text {th }}$ International Conference on Soil Mechanics and Geotechnical Engineering, Paris, France.

Fredlund, M.D. 2000. The role of unsaturated soil property functions in the practice of unsaturated soil mechanics. Dissertation, University of Saskatchewan, Saskatoon, Saskatchewan.

Gardner, W. R. 1974. The permeability problem. Soil Science, 117(5): 243-249.

Haines, W. B. 1923. The volume-changes associated with variations of water content in soil. The Journal of agricultural science, 13(03): 296-310.

Huang, S., Barbour, S.L., and Fredlund, D.G. 1998. Development and verification of a coefficient of permeability function for a deformable unsaturated soil. Canadian Geotechnical Journal, 35(3): 411-425.

Kim, D.J., Vereecken, H., Feyen, J., Boels, D., and Bronswijk, J.J.B. 1992. On the characterization of properties of an unripe marine clay soil: I. Shrinkage processes of an unripe marine clay soil in relation to physical ripening, Soil Science, 153(6): 471-481. 
Leong, E.C., and Rahardjo, H. 1997. Permeability functions for unsaturated soils. Journal of Geotechnical and Geoenvironmental Engineering, 123(12): 1118-1126.

Marinho, F.A.M. 1994. Shrinkage behaviour of some plastic soils. Doctoral dissertation, University of London, UK.

Mbonimpa, M., Aubertin, M., Maqsoud, A., and Bussière, B. 2006. Predictive model for the water retention curve of deformable clayey soils. Journal of Geotechnical and Geoenvironmental Engineering, 132(9): 1121-1132.

Mualem, Y. 1976. A new model for predicting the hydraulic conductivity of unsaturated porous media. Water Resources Research, 12(3): 513-522.

Nuth, M., and Laloui, L. 2008. Advances in modeling hysteretic water retention curve in deformable soils. Computers and Geotechnics, 35(6): 835-844.

Parent, S.E., Cabral, A., and Zornberg, J.G. 2007. Water retention curve and hydraulic conductivity function of highly compressible materials. Canadian Geotechnical Journal, 44(10): 1200-1214.

Rahimi, A., Rahardjo, H., and Leong, E.C. 2015. Effects of soil-water characteristic curve and relative permeability equations on estimation of unsaturated permeability function. Soils and Foundations, 55(6): 1400-1411.

Rodriguez, R. 2006. Hydrogeotechnical characterization of a metallurgical waste. Canadian Geotechnical Journal, 43(10): 1042-1060.

Saleh-Mbemba, F., Aubertin, M., Mbonimpa, M., and Li, L. 2016. Experimental characterization of the shrinkage and water retention behavior of tailings from hard rock mines. Geotechnical and Geological Engineering, 34(1): 251-266.

Sobkowicz, J.C., and Morgenstern, N.R. 2009. A geotechnical perspective on oil sands tailings. Proceedings of the Thirteenth International Conference on Tailings and Mine Waste, xvii-xl. 
Somogyi, F. 1980. Large-strain consolidation of fine-grained slurries. Proceedings of the Canadian Society for Civil Engineering 1980 Annual Conference, Winnipeg, Manitoba, Canada.

Sridharan, A., and Rao, G.V. 1971. Effective stress theory of shrinkage phenomena. Canadian Geotechnical Journal, 8(4): 503-513.

Tami, D., Rahardjo, H, and Leong, E.C. 2004. Effects of hysteresis on steady-state infiltration in unsaturated slopes. Journal of Geotechnical and Geoenvironmental Engineering, ASCE, 130 (9): 956-967.

Taylor, D.W. 1948. Fundamentals of soil mechanics. J. Wiley \& Sons; London: Chapman \& Hall. Tempany, H.A. 1917. The shrinkage of soils. The Journal of Agricultural Science, 8(03): 312330.

Terzaghi, K. 1925. Principles of soil mechanics, IV -- Settlement and consolidation of clay. Engineering News-Record, 95(3): 874-878.

Tripathy, S., Tadza, M.Y.M., and Thomas, H.R. 2014. Soil-water characteristic curves of clays. Canadian Geotechnical Journal, 51(8): 869-883.

Van Genuchten, M.T. 1980. A closed-form equation for predicting the hydraulic conductivity of unsaturated soils. Soil science society of America journal, 44(5): 892-898.

Zhang, F-X, Fredlund, D. G., Wilson, G. W., and Sedgwick, A. 2014. Determination of the permeability function for drying oil sands tailings undergoing volume change and desaturation. Proceedings of the $4^{\text {th }}$ International Oil Sands Tailings Conference, Banff, A.B.Dec $7^{\text {th }}-10^{\text {th }}, 2014$.

Zhang, F-X, and Fredlund, D.G. 2015. Examination of the estimation of relative permeability for unsaturated soils. Canadian Geotechnical Journal, 52(12): 2077-2087.

Zhang, F., Fredlund, D.G., and Wilson, G.W. 2016. "Water Permeability Function for Soils that Undergo Volume Change as Suction Changes”. Indian Geotechnical Journal. 46 (3): 210227. doi:10.1007/s40098-016-0187-5. 
Zhang, L., and Chen, Q. 2005. Predicting bimodal soil-water characteristic curves. Journal of Geotechnical and Geoenvironmental Engineering, 131(5): 666-670. 


\section{Figures}

Figure 1. Fredlund-Xing (1994) SWCC fit to experimental data for Columbia sandy silt (Data from Brooks and Corey 1964).

Figure 2. Gravimetric water content, instantaneous volumetric water content and degree of saturation versus soil suction for thickened oil sands tailings tested

Figure 3. Shrinkage curve for thickened oil sands tailings

Figure 4. Gravimetric water content versus soil suction thickened oil sands tailings.

Figure 5. Measured data of saturated permeability versus void ratio and its best-fitting curves for thickened oil sands tailings

Figure 6. Void ratio versus soil suction for thickened oil sands tailings.

Figure 7. Degree of saturation versus soil suction for thickened oil sands tailings.

Figure 8. Instantaneous volumetric water content versus soil suction for thickened oil sands tailings.

Figure 9. Relative permeability versus soil suction for thickened oil sands tailings.

Figure 10. Relative permeability versus soil suction obtained from S-SWCC using different lower limits of integration for thickened oil sands tailings.

Figure 11. Relative permeability versus soil suction obtained from two best-fitting S-SWCCs for thickened oil sands tailings.

Figure 12. Relative permeability versus soil suction for thickened oil sands tailings.

Figure 13. Reference saturated permeability versus soil suction for thickened oil sands tailings.

Figure 14. Coefficient of permeability versus soil suction for thickened oil sands tailings. 
Appendix A: Procedure when estimating the permeability function of a high-volumechange soil with a unimodal w-SWCC using the revised methodology.

Step 1. Obtain fitting parameters for $w$-SWCC.

$$
\begin{gathered}
w(\psi)=\frac{w_{\mathrm{s}}\left(1-\ln \left(1+\psi / \psi_{\mathrm{r}}\right) / \ln \left(1+10^{6} / \psi_{\mathrm{r}}\right)\right)}{\left(\ln \left(\exp (1)+\left(\psi / a_{\mathrm{f}}\right)^{n_{\mathrm{f}}}\right)\right)^{m_{\mathrm{f}}}} \\
w(\psi)=w_{\mathrm{s}}\left(1-\frac{\ln \left(1+\frac{\psi}{\psi_{\mathrm{rb}}}\right)}{\ln \left(1+\frac{10^{6}}{\psi_{\mathrm{rb}}}\right)}\right)\left(\frac{p}{\left(\ln \left(\exp (1)+\left(\frac{\psi}{a_{\mathrm{f} 1}}\right)^{n_{\mathrm{f} 1}}\right)\right)^{m_{\mathrm{f} 1}}}+\frac{1-p}{\left(\ln \left(\exp (1)+\left(\frac{\psi}{a_{\mathrm{f} 2}}\right)^{n_{\mathrm{f} 2}}\right)\right)^{m_{\mathrm{f} 2}}}\right)
\end{gathered}
$$

[A-

2]

Eq. [A-1] is recommended for best-fitting unimodal experimental data; Eq. [A-2] is for bimodal measured data.

Step 2. Obtain fitting parameters for the shrinkage curve.

$$
e(w)=a_{\mathrm{sh}}\left(\left(\frac{w}{b_{\mathrm{sh}}}\right)^{c_{\mathrm{sh}}}+1\right)^{\frac{1}{c_{\mathrm{sh}}}}
$$

Step 3. Calculate the void ratio versus soil suction relationship.

$$
e(\psi)=a_{\mathrm{sh}}\left(\left(\frac{w_{\mathrm{s}}\left(1-\ln \left(1+\psi / \psi_{\mathrm{r}}\right) / \ln \left(1+10^{6} / \psi_{\mathrm{r}}\right)\right)}{b_{\mathrm{sh}}\left(\ln \left(\exp (1)+\left(\psi / a_{\mathrm{f}}\right)^{n_{\mathrm{f}}}\right)\right)^{m_{\mathrm{f}}}}\right)^{c_{\mathrm{sh}}}+1\right)^{\frac{1}{c_{\mathrm{sh}}}}
$$

4]

Step 4. Calculate the S-SWCC. 


$$
S(\psi)=\frac{G_{\mathrm{s}} w_{\mathrm{s}}\left(1-\ln \left(1+\psi / \psi_{\mathrm{r}}\right) / \ln \left(1+10^{6} / \psi_{\mathrm{r}}\right)\right)}{a_{\mathrm{sh}}\left(\ln \left(\exp (1)+\left(\psi / a_{\mathrm{f}}\right)^{n_{\mathrm{f}}}\right)\right)^{m_{\mathrm{f}}}\left(\left(\frac{w_{\mathrm{s}}\left(1-\ln \left(1+\psi / \psi_{\mathrm{r}}\right) / \ln \left(1+10^{6} / \psi_{\mathrm{r}}\right)\right)}{b_{\mathrm{sh}}\left(\ln \left(\exp (1)+\left(\psi / a_{\mathrm{f}}\right)^{n_{\mathrm{f}}}\right)\right)^{m_{\mathrm{f}}}}\right)^{c_{\mathrm{sh}}}+1\right)^{\frac{1}{c_{\mathrm{sh}}}}}
$$

[A-

5]

Step 5. Calculate the $\theta_{\mathrm{i}}$-SWCC.

$$
\theta_{\mathrm{i}}(\psi)=\frac{G_{\mathrm{s}} w_{\mathrm{s}}\left(1-\ln \left(1+\psi / \psi_{\mathrm{r}}\right) / \ln \left(1+10^{6} / \psi_{\mathrm{r}}\right)\right)}{\left(\ln \left(\exp (1)+\left(\psi / a_{\mathrm{f}}\right)^{n_{\mathrm{f}}}\right)\right)^{m_{\mathrm{f}}}\left(1+a_{\mathrm{sh}}\left(\left(\frac{w_{\mathrm{s}}\left(1-\ln \left(1+\psi / \psi_{\mathrm{r}}\right) / \ln \left(1+10^{6} / \psi_{\mathrm{r}}\right)\right)}{b_{\mathrm{sh}}\left(\ln \left(\exp (1)+\left(\psi / a_{\mathrm{f}}\right)^{n_{\mathrm{f}}}\right)\right)^{m_{\mathrm{f}}}}\right)^{c_{\mathrm{sh}}}+1\right)^{\frac{1}{c_{\mathrm{sh}}}}\right)}
$$

[A-

6]

Step 6. Calculate the relative coefficient of permeability function from S-SWCC data starting at AEV with Eq. [A-7]. Use Eq. [A-5] for the best-fitting of the S-SWCC.

$$
k_{\mathrm{r}}^{s}(\psi)=\frac{\int_{\ln (\psi)}^{\mathrm{b}} \frac{S\left(e^{y}\right)-S(\psi)}{e^{y}} S^{\prime}\left(e^{y}\right) d y}{\int_{\ln \left(\psi_{\mathrm{aev}}\right)}^{b} \frac{S\left(e^{y}\right)-S\left(\psi_{\mathrm{aev}}\right)}{e^{y}} S^{\prime}\left(e^{y}\right) d y}
$$

Step 7. Calculate the change in the reference saturated permeability function due to volume change.

$$
k_{\mathrm{rs}}(\psi)=A\left(a_{\mathrm{sh}}\left(\left(\frac{w_{\mathrm{s}}\left(1-\ln \left(1+\psi / \psi_{\mathrm{r}}\right) / \ln \left(1+10^{6} / \psi_{\mathrm{r}}\right)\right)}{b_{\mathrm{sh}}\left(\ln \left(\exp (1)+\left(\psi / a_{\mathrm{f}}\right)^{n_{\mathrm{f}}}\right)\right)^{m_{\mathrm{f}}}}\right)^{c_{\mathrm{sh}}}+1\right)^{\frac{1}{c_{\mathrm{sh}}}}\right)^{B}
$$

Step 8. Calculate the permeability function for a soil that changes volume as soil suction is increased considering both desaturation and volume change with Eq. [A-9] using Eq. [A-4] for $e(\psi)$ and Eq. [A-5] for $S(\psi)$. 


$$
k(\psi)=\frac{A(e(\psi))^{B} \int_{\ln (\psi)}^{\mathrm{b}} \frac{S\left(e^{y}\right)-S(\psi)}{e^{y}} S^{\prime}\left(e^{y}\right) d y}{\int_{\ln \left(\psi_{\text {aev }}\right)}^{b} \frac{S\left(e^{y}\right)-S\left(\psi_{\text {aev }}\right)}{e^{y}} S^{\prime}\left(e^{y}\right) d y}
$$




\section{Tables}

Table 1. Breaking point on different SWCCs

\begin{tabular}{cccc}
\hline Type of SWCC & $w$-SWCC & S-SWCC & $\theta_{\mathrm{i}-S W C C}$ \\
\hline $\begin{array}{c}\text { Suction at the first } \\
\text { breaking point }\end{array}$ & $0.113 \mathrm{kPa}$ & $111 \mathrm{kPa}$ & $0.183 \mathrm{kPa}$ \\
\hline
\end{tabular}

Table 2. Difference in the estimated relative permeability in terms of orders of magnitude between using the AEV and using a different lower limit of integration.

\begin{tabular}{cccc}
\hline Lower limit of integration & $0.1 \mathrm{kPa}$ & $1 \mathrm{kPa}$ & $10 \mathrm{kPa}$ \\
\hline $\begin{array}{c}\text { Difference in terms of orders } \\
\text { of magnitude }\end{array}$ & 2.38 & 1.83 & 0.90 \\
\hline
\end{tabular}




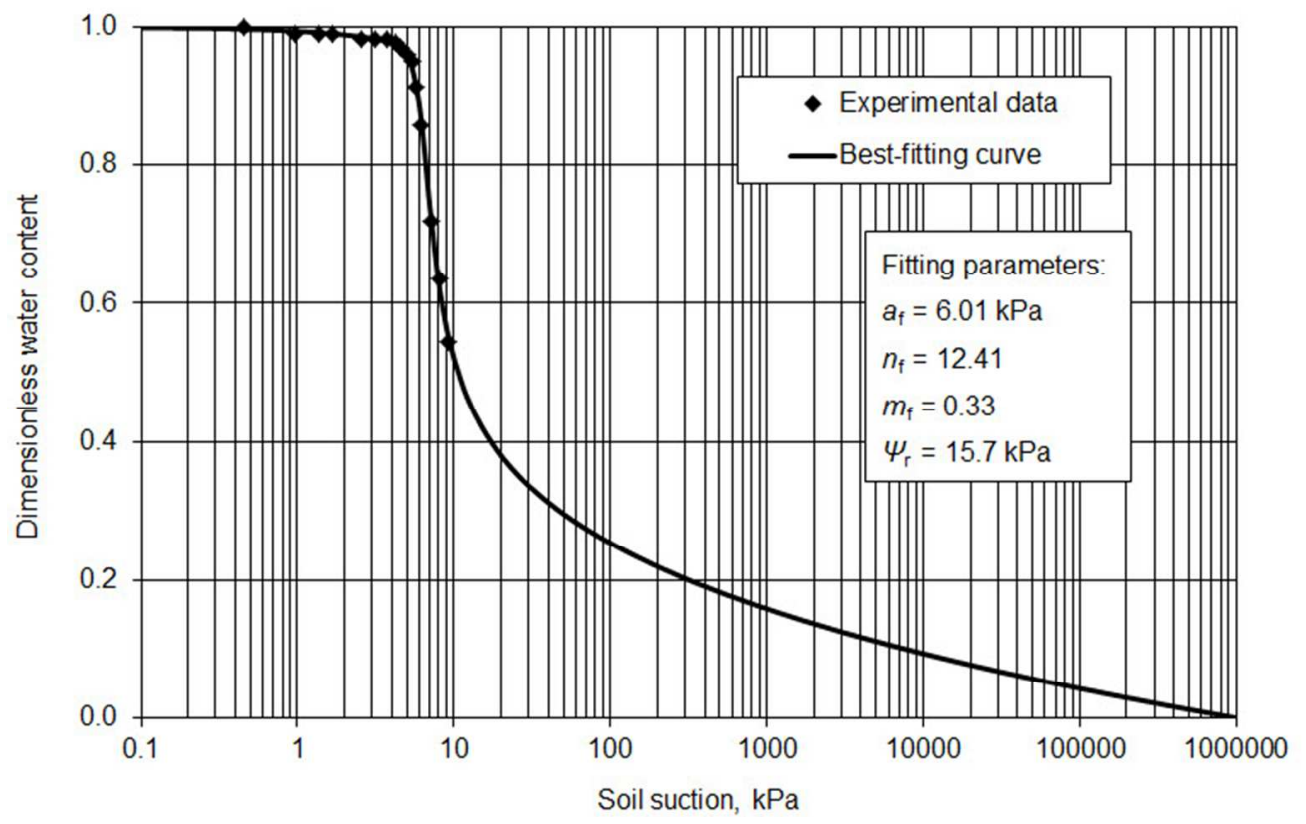

Figure 1. Fredlund-Xing (1994) SWCC fit to experimental data for Columbia sandy silt (Data from Brooks and Corey (1964)).

$202 \times 126 \mathrm{~mm}$ (96 x 96 DPI) 


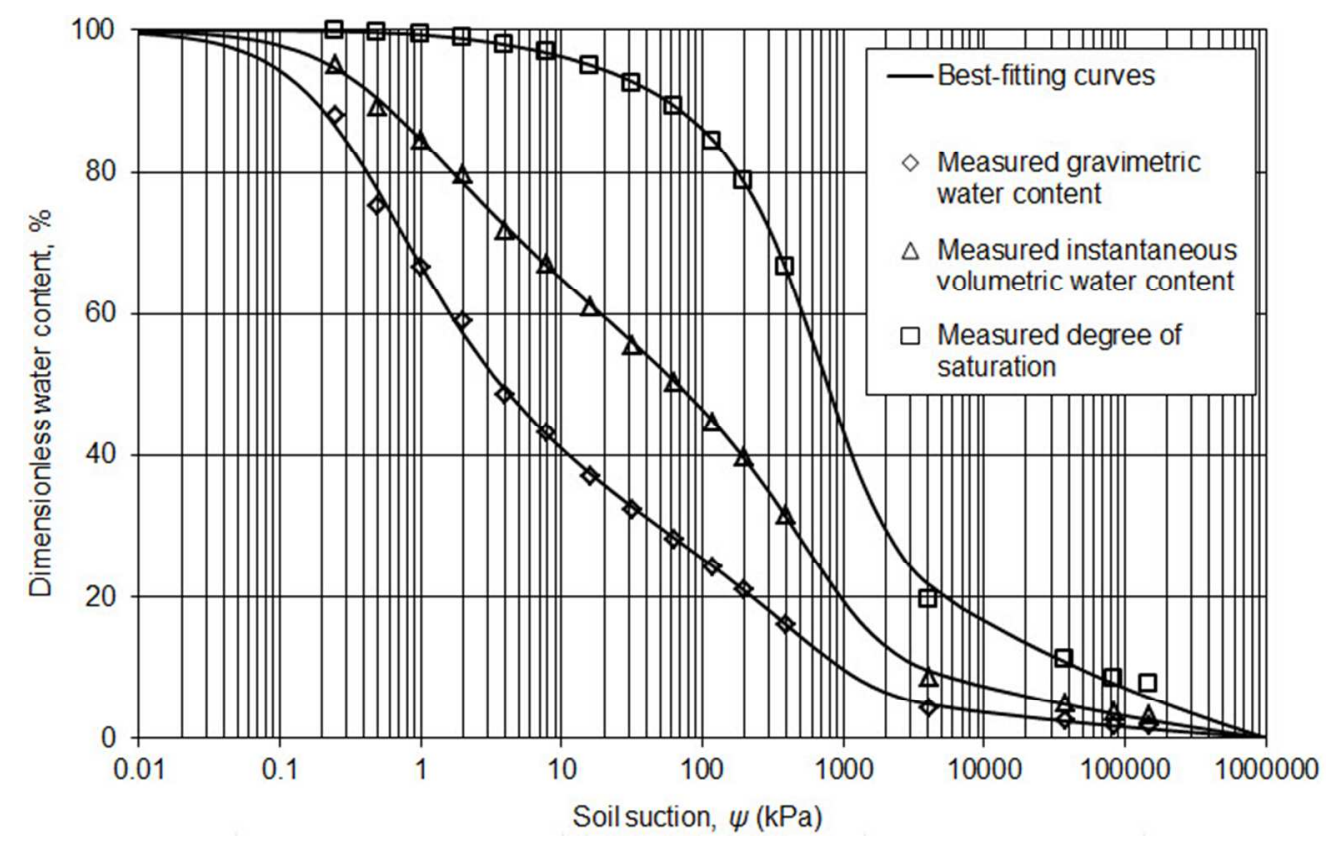

Figure 2. Gravimetric water content, instantaneous volumetric water content and degree of saturation versus soil suction for thickened oil sands tailings tested

$197 \times 124 \mathrm{~mm}(96 \times 96 \mathrm{DPI})$ 


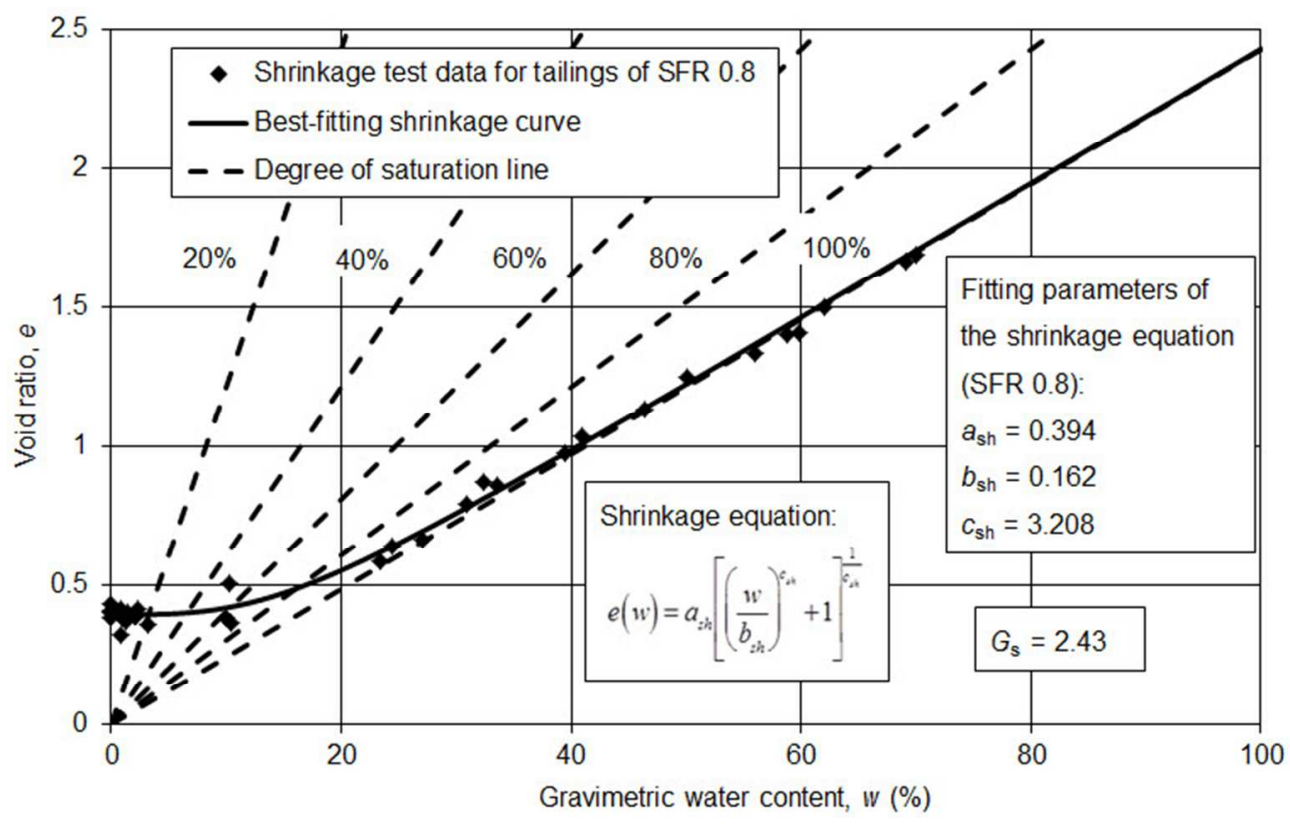

Figure 3. Shrinkage curve for thickened oil sands tailings

$202 \times 126 \mathrm{~mm}(96 \times 96$ DPI) 


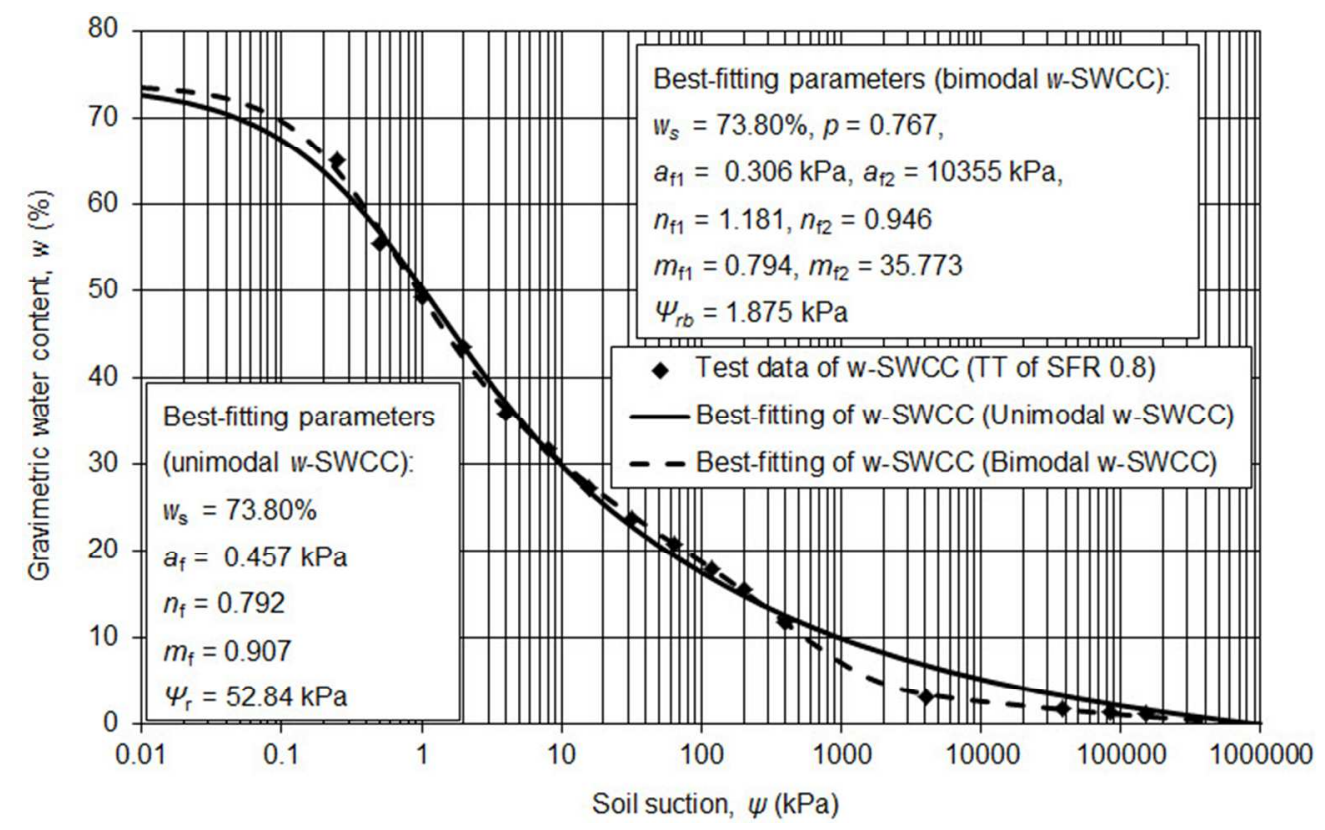

Figure 4. Gravimetric water content versus soil suction thickened oil sands tailings.

$202 \times 126 \mathrm{~mm}(96 \times 96$ DPI $)$ 


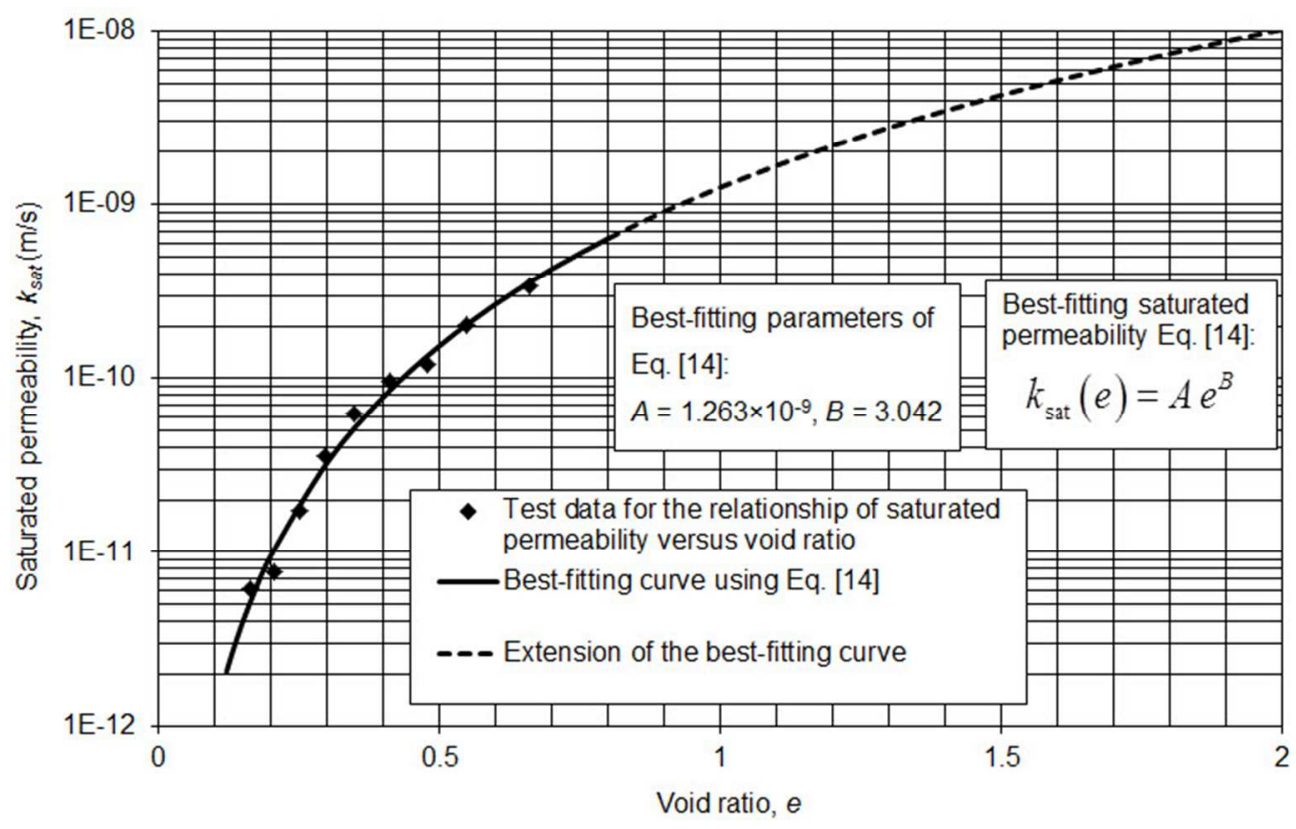

Figure 5. Measured data of saturated permeability versus void ratio and its best-fitting curves for thickened oil sands tailings

$202 \times 126 \mathrm{~mm}(96 \times 96$ DPI $)$ 


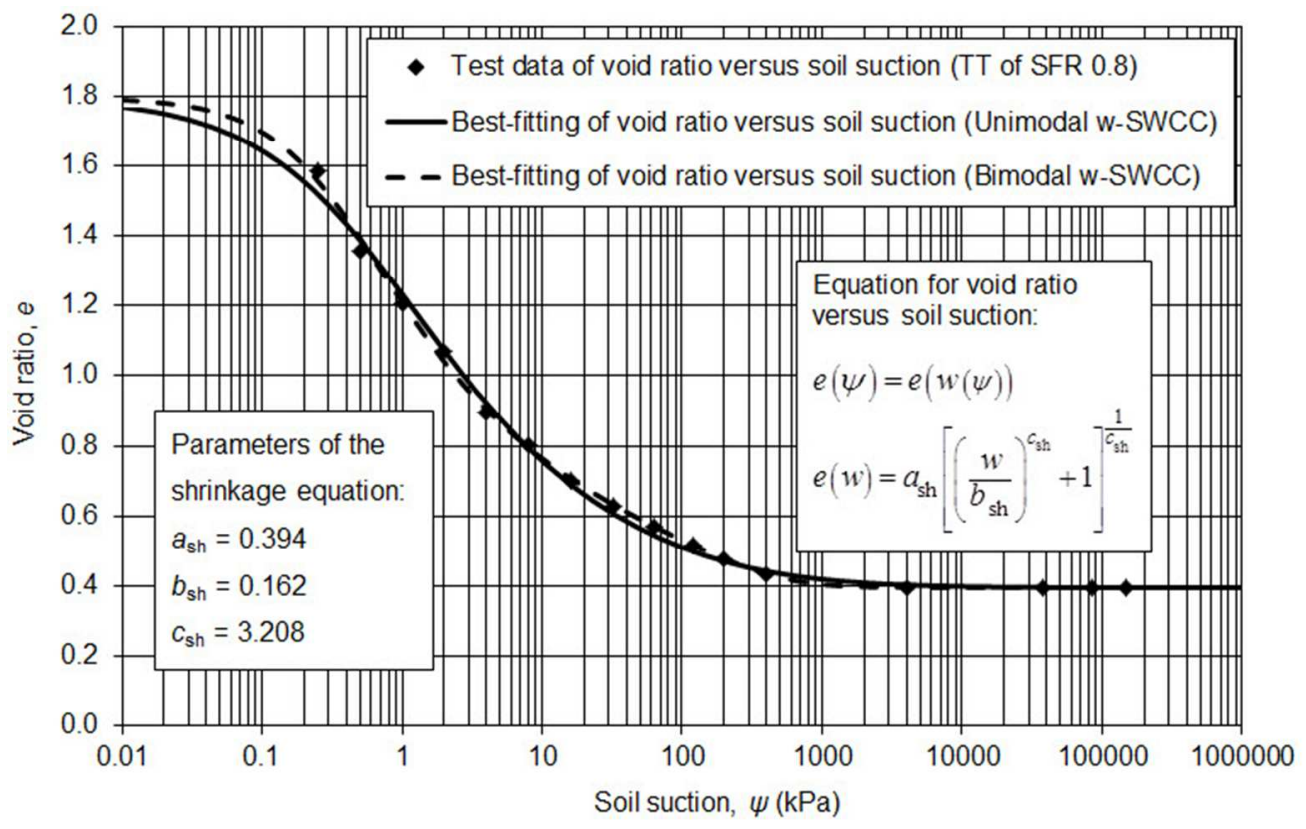

Figure 6. Void ratio versus soil suction for thickened oil sands tailings.

$202 \times 126 \mathrm{~mm}(96 \times 96 \mathrm{DPI})$ 


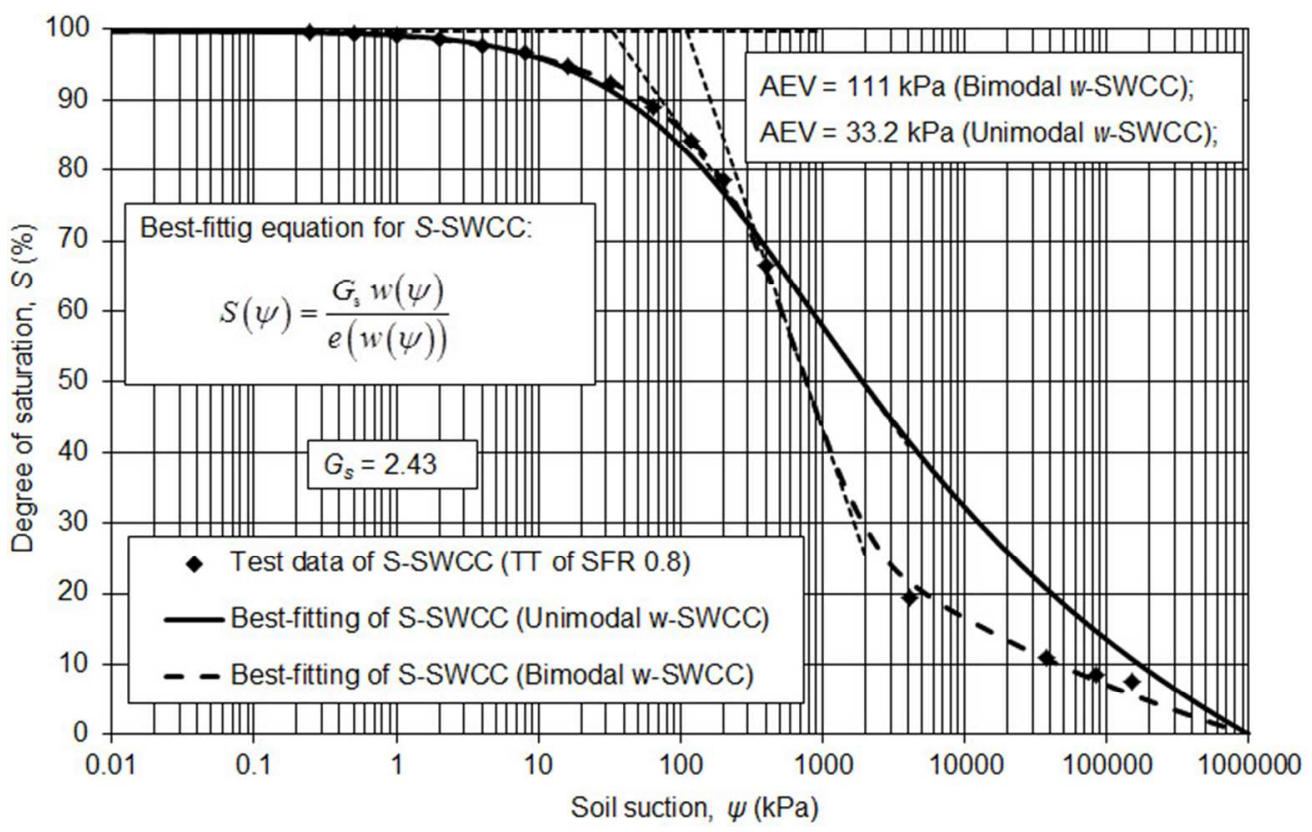

Figure 7. Degree of saturation versus soil suction for thickened oil sands tailings.

$201 \times 126 \mathrm{~mm}(96 \times 96$ DPI $)$ 


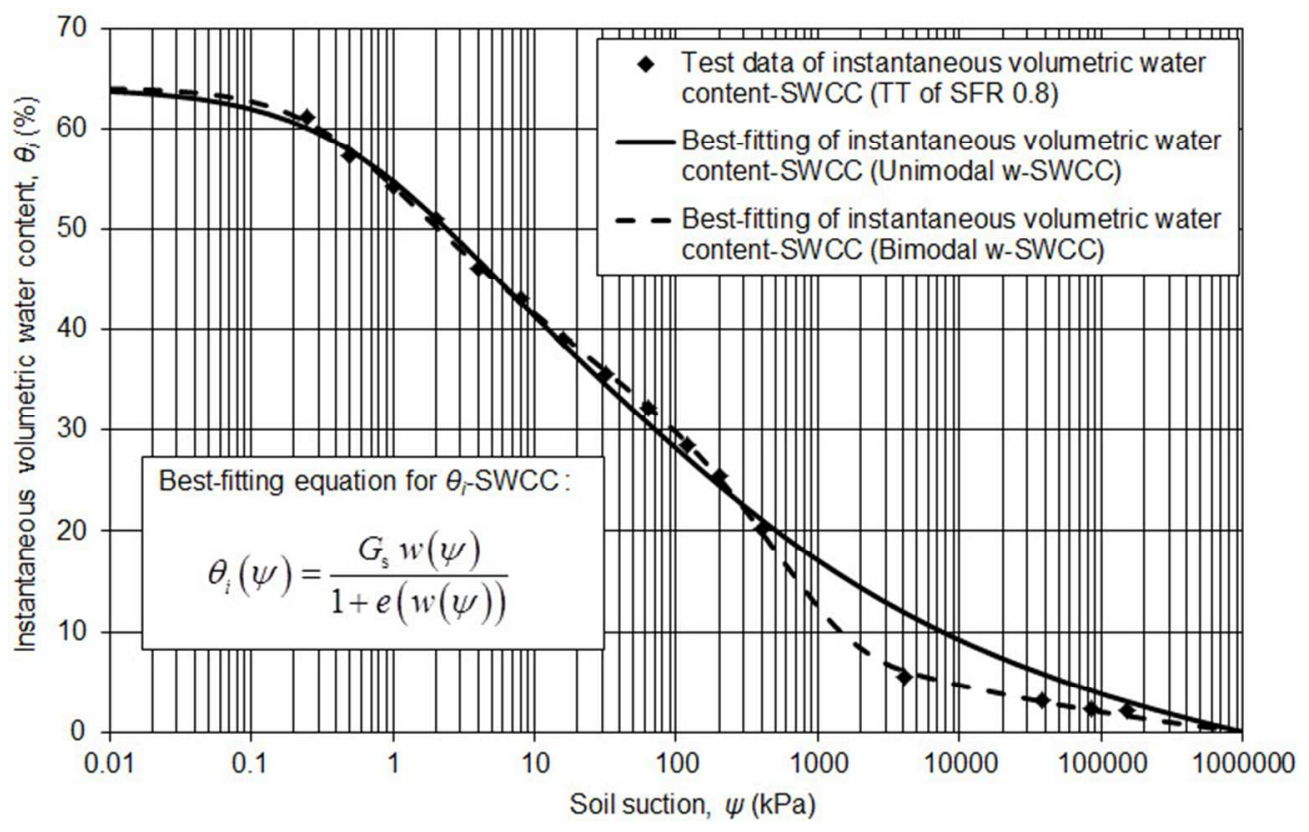

Figure 8. Instantaneous volumetric water content versus soil suction for thickened oil sands tailings.

$202 \times 126 \mathrm{~mm}(96 \times 96 \mathrm{DPI})$ 


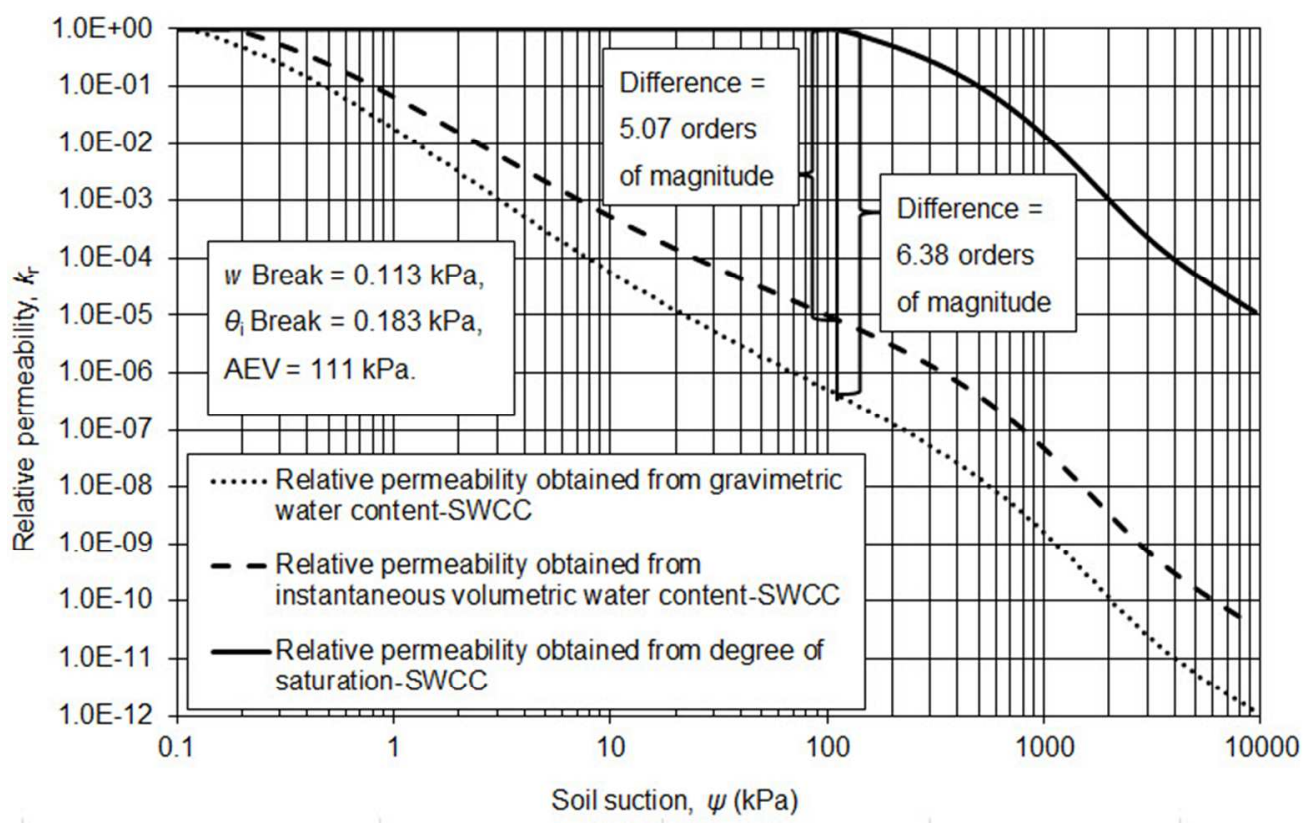

Figure 9. Relative permeability versus soil suction for thickened oil sands tailings.

$$
202 \times 127 \mathrm{~mm}(96 \times 96 \text { DPI) }
$$




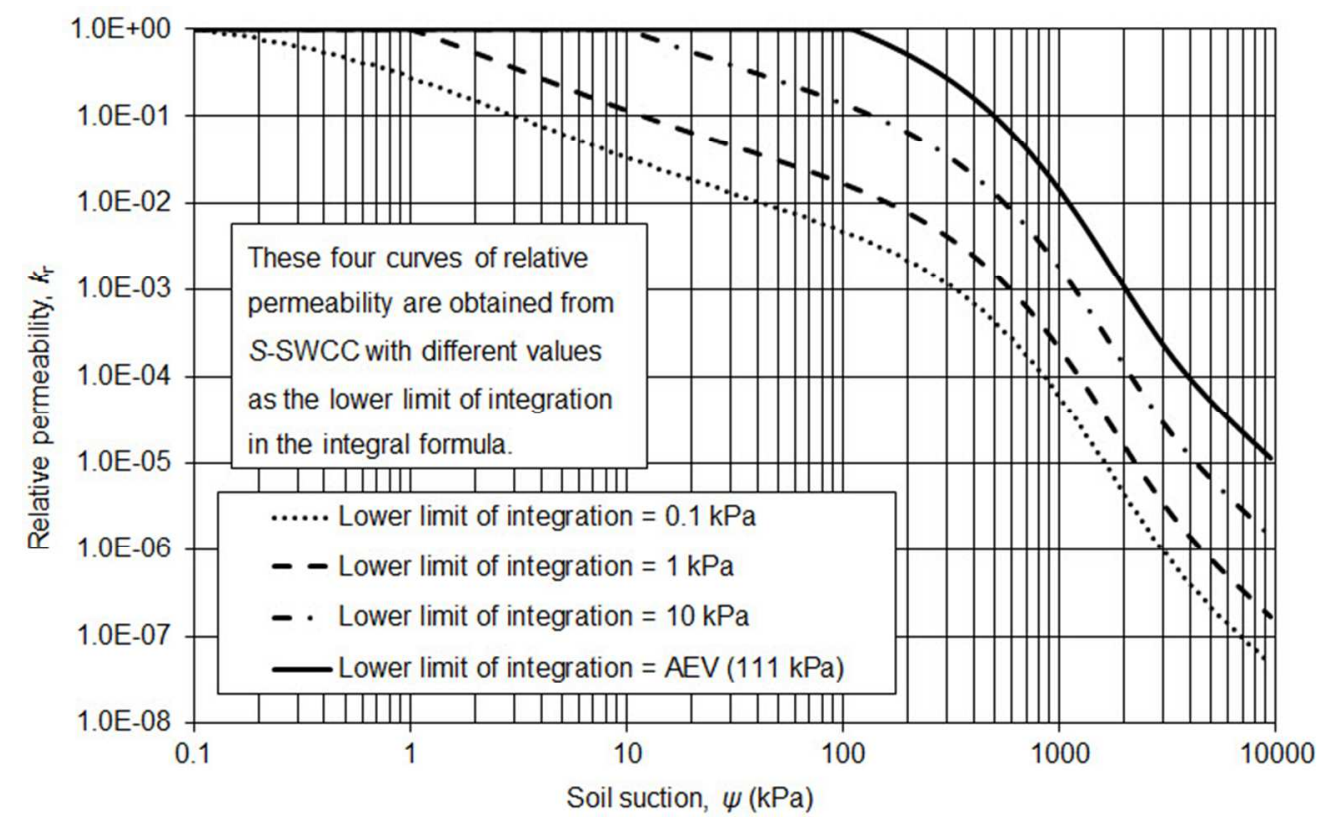

Figure 10. Relative permeability versus soil suction obtained from S-SWCC using different lower limits of integration for thickened oil sands tailings.

$202 \times 126 m m(96 \times 96$ DPI) 


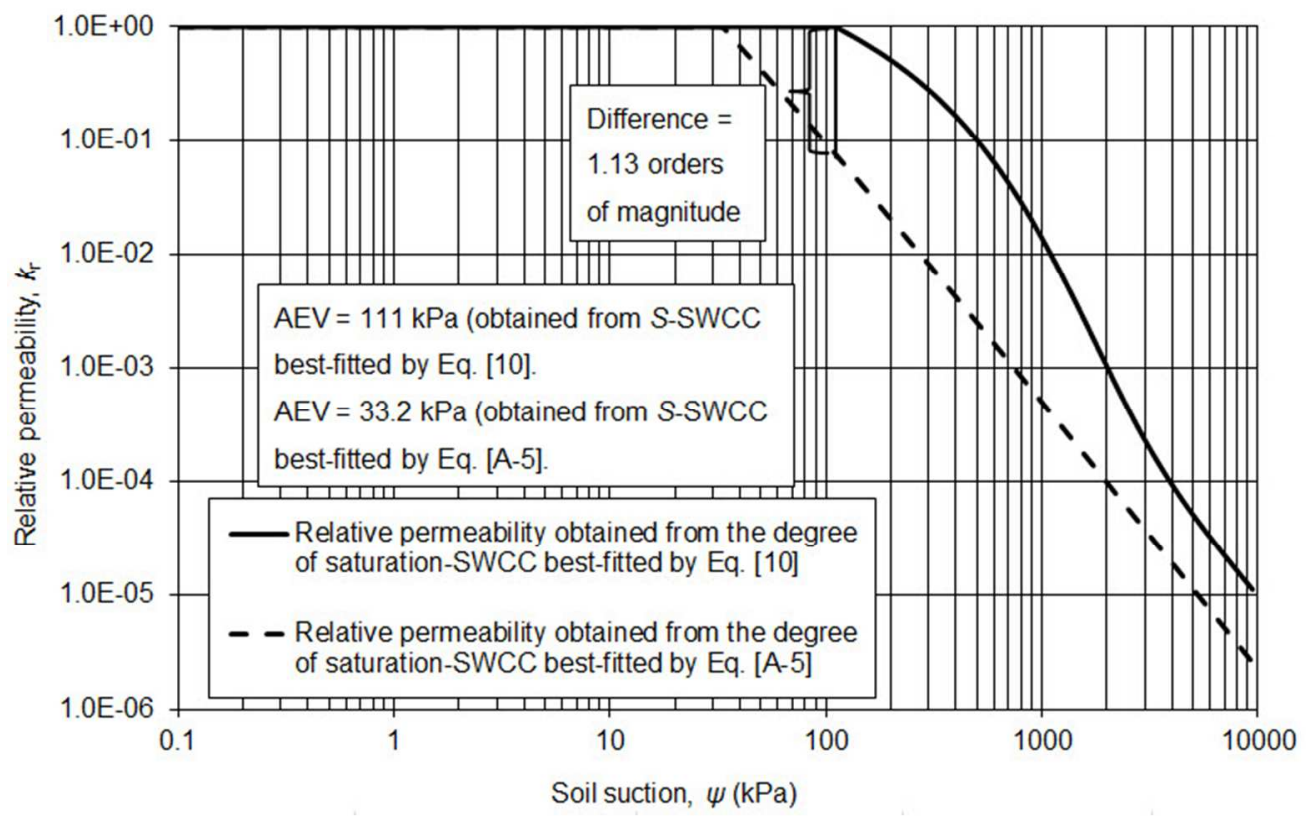

Figure 11. Relative permeability versus soil suction obtained from two best-fitting S-SWCCs for thickened oil sands tailings.

$203 \times 127 m m(96 \times 96$ DPI $)$ 


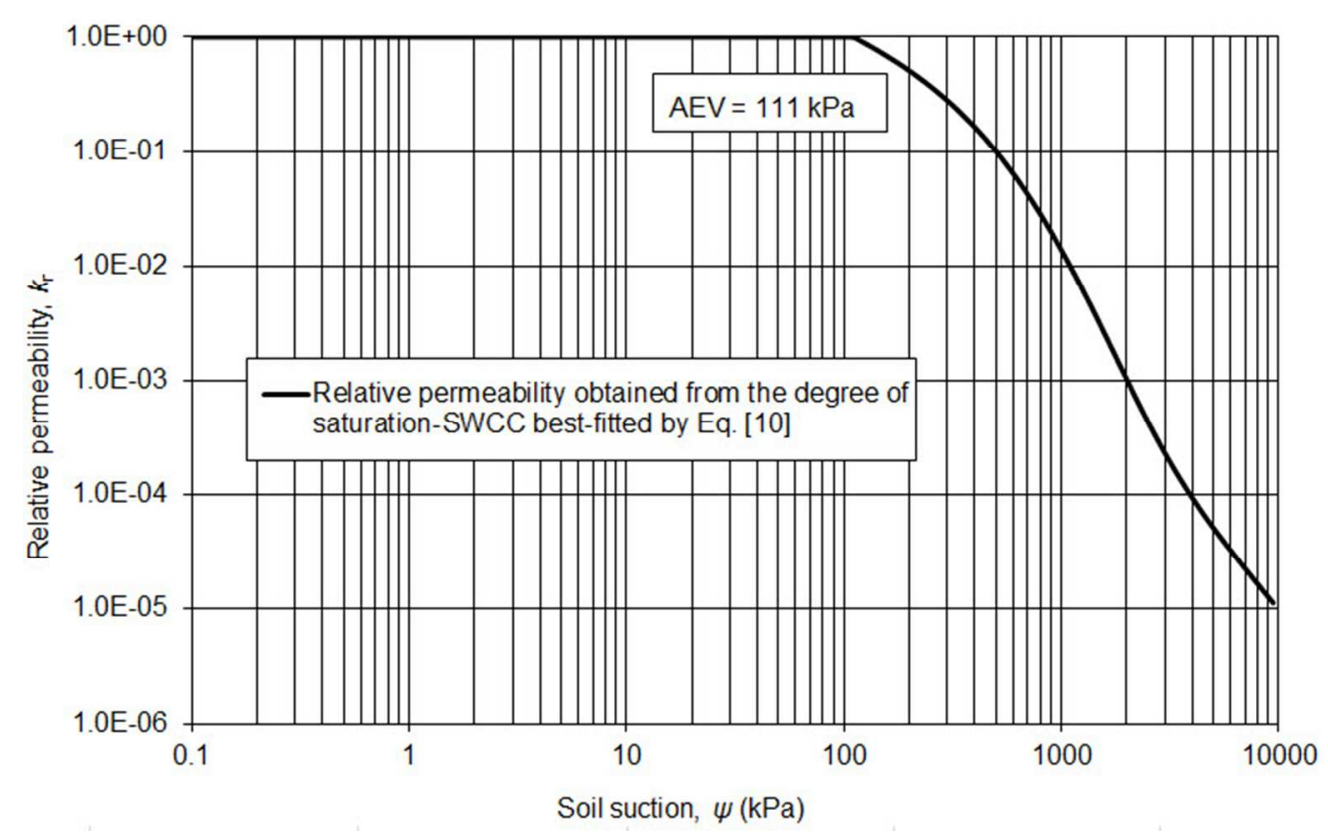

Figure 12. Relative permeability versus soil suction for thickened oil sands tailings. $201 \times 127 \mathrm{~mm}(96 \times 96 \mathrm{DPI})$ 


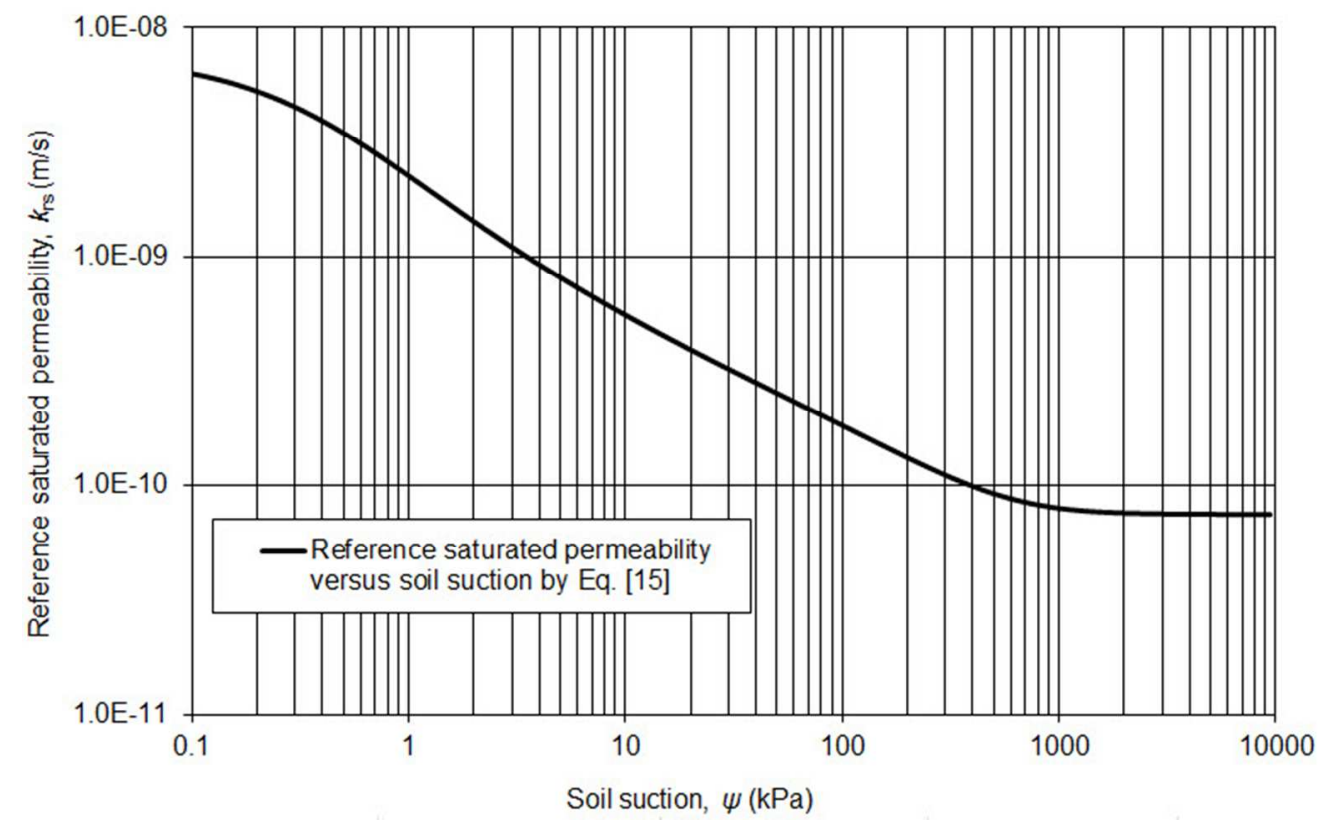

Figure 13. Reference saturated permeability versus soil suction for thickened oil sands tailings.

$202 \times 127 \mathrm{~mm}(96 \times 96$ DPI $)$ 


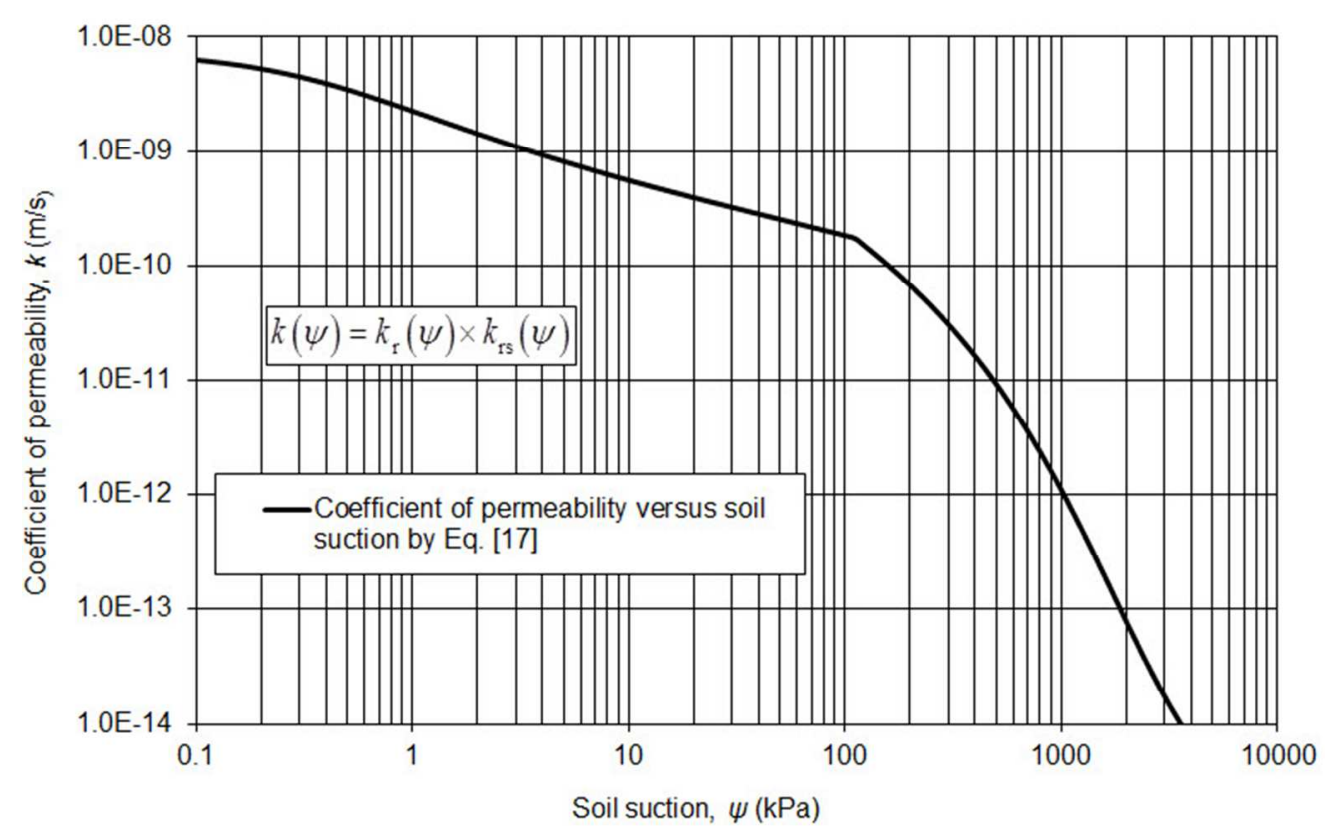

Figure 14. Coefficient of permeability versus soil suction for thickened oil sands tailings. $201 \times 126 \mathrm{~mm}(96 \times 96$ DPI $)$ 